\title{
Superoxide Production in Rat Hippocampal Neurons: Selective Imaging with Hydroethidine
}

\author{
Vytautas P. Bindokas, Joaquín Jordán, Chong C. Lee, and Richard J. Miller \\ Department of Pharmacological and Physiological Sciences, The University of Chicago, Chicago, Illinois 60637
}

Digital-imaging microfluorimetry of the oxidation of hydroethidine (HEt) to ethidium can be used to monitor superoxide $\left(\mathrm{O}_{2}^{-}\right)$production selectively within individual rat hippocampal pyramidal neurons in culture and in brain slices. Under assay conditions, oxidation was not accomplished by hydroxyl radical, singlet $\mathrm{O}_{2}, \mathrm{H}_{2} \mathrm{O}_{2}$, or nitrogen radicals. Neuronal $\mathrm{O}_{2}^{-}$ production varied with metabolic activity and age. $\mathrm{O}_{2}^{-}$generation increased after treatment with AMPA, kainic acid, and NMDA, and the mitochondrial uncoupler carbonylcyanide $\mathrm{p}$-(trifluoromethoxy)phenyl hydrazone, but usually not after depolarization $\left(50 \mathrm{~mm} \mathrm{~K}{ }^{+}\right) . \mathrm{O}_{2}^{-}$concentrations were sensitive to scavengers and nitric oxide. HEt oxidation was higher in $\mathrm{Ca}^{2+}$-containing versus $\mathrm{Ca}^{2+}$-free saline. However, $\mathrm{Ca}^{2+}$ ionophores did not increase oxidation greatly. $\mathrm{H}_{2} \mathrm{O}_{2}$ application produced a secondary increase in $\mathrm{O}_{2}^{-}$. The major source of $\mathrm{O}_{2}^{-}$under basal and stimulated conditions appeared to be the mitochondria. Consistent with this, ethidium staining in dendrites was punctate, colocalized with mitochondria, and blocked by $\mathrm{CN}^{-}$.

Key words: reactive oxygen species; free radicals; excitotoxicity; $\mathrm{H}_{2} \mathrm{O}_{2}$; microfluorimetry; NMDA; mitochondria; NOS; dihydroethidium
Neurons generate reactive oxygen species (ROS) by virtue of oxidative metabolism and increased ROS production during excitotoxic damage, hypoxia, reperfusion, etc. (Ikeda and Long, 1990; Coyle and Puttfarcken, 1993; Lafon-Cazal et al., 1993; Culcasi et al., 1994). ROS are implicated in the neurodegeneration associated with aging, Alzheimer's disease, and acute states such as cerebral ischemia (Halliwell, 1989; Siesjö et al., 1989; Traystman et al., 1991; Coyle and Puttfarken, 1993). However, the precise contribution of different oxygen radicals to various diseases is unclear. Some radicals also have important functions as second messengers (Ignarro, 1990; Lipton et al., 1993; Maines, 1993; Dawson and Snyder, 1994). Thus, these molecules play a central role in the life and death of neurons.

Neuronal ROS include superoxide $\left(\mathrm{O}_{2}^{-}\right)$, hydroxyl radical $(\cdot \mathrm{OH})$, singlet $\mathrm{O}_{2}$, and hydrogen peroxide $\left(\mathrm{H}_{2} \mathrm{O}_{2}\right)$ (cf. Halliwell and Gutteridge, 1984; Siesjö et al., 1989). $\mathrm{H}_{2} \mathrm{O}_{2}$ and $\mathrm{NO}$ are freely permeable. $\mathrm{O}_{2}^{-}$may pass through membranes only via anion channels (Lynch and Fridovich, 1978), is not a particularly reactive species, acts as an electrophile or nucleophile, and potentially forms more reactive species via secondary reactions (cf. Halliwell and Gutteridge, 1984). It inhibits enzymes including glutathione peroxidase, catalase, and creatine kinase. Sources of $\mathrm{O}_{2}^{-}$include the following: nitric oxide synthase (NOS) (Pou et al., 1992; Culcasi et al., 1994); NADPH oxidase (Rossi, 1986); monooxygenases and NADH dehydrogenase (cf. Turrens et al., 1985); dihydro-orotate dehydrogenase (Forman and Kennedy, 1976); cyclo-oxygenase, lipoxygenases, and xanthine oxidase (XO) (cf.

\footnotetext{
Received June 23, 1995; revised Nov. 1, 1995; accepted Nov. 30, 1995.

This work was supported by National Institutes of Health Grants DA02121, MH40165, DA02575, and by Bayer. J.J. was supported by the Spanish Ministry of Education and Science and a NATO Fellowship. C.C.L. was supported by University of Chicago, Pharmacol Sci Res Training Grant 5-T32-GM07151-21. We thank Maria F. Galindo and Charles J. Marcuccilli for preparing hippocampal neurons and secondary glia cultures.

Correspondence should be addressed to Richard J. Miller, Wm. Mabie Professor of Neuroscience, Department of Pharmacological and Physiological Sciences, University of Chicago, 947 East 58th Street, Chicago, IL 60637.

Copyright (C) 1996 Society for Neuroscience $0270-6474 / 96 / 161324-13 \$ 05.00 / 0$
}

Siesjö et al., 1989); and components of the electron transport chain (Nohl and Hegner, 1978; Turrens et al., 1985; Nohl, 1990). $\mathrm{O}_{2}^{-}$is converted to $\mathrm{H}_{2} \mathrm{O}_{2}$ spontaneously or by action of superoxide dismutase (SOD). $\mathrm{NO}$ reacts with $\mathrm{O}_{2}^{-}$to form the powerful oxidant peroxynitrite. Reaction of $\mathrm{H}_{2} \mathrm{O}_{2}$ and peroxynitrite can give rise to highly reactive $\mathrm{OH}$ (Cadenas, 1989; Hogg et al., 1992). Enzymatic (SODs, catalase, etc.) and scavenging (glutathione, ascorbate, tocopherol, etc.) pathways (cf. Cadenas, 1989) remove most ROS.

Current ROS probes include colorimetric as well as luminescence assays (Nakano, 1990; Tanaka et al., 1994). The former include reduction of cytochrome $c$ or analogs, nitroblue tetrazolium, diaminobenzidine- $\mathrm{Mn}^{2+}$, and the hydroxylammonium chloride/sulfanic acid assay (Elstner and Heupel, 1976; Key et al., 1990; Steinbeck et al., 1993). Other methods use luminol quench by $\mathrm{O}_{2}^{-}$(Lissi et al., 1994) and a recently developed $\mathrm{O}_{2}^{-}$electrode (Fabian et al., 1995). A drawback of most of these methods is the requirement that $\mathrm{ROS}$ exit cells for detection. This hampers detection of highly reactive species and those, like $\mathrm{O}_{2}^{-}$, that pass poorly across membranes. Dichlorofluorescein (DCFH) and similar fluorescent derivatives commonly are believed to be selective for $\mathrm{H}_{2} \mathrm{O}_{2}$, but other effective oxidants include lipid peroxides and -OH, but not $\mathrm{O}_{2}^{-}$(Bass et al., 1983; Cathcart et al., 1983). DCFH is a high-affinity substrate for XO (Zhu et al., 1994). Further drawbacks of fluorescein-based derivatives are high rates of autooxidation, photoconversion, photobleaching, $\mathrm{pH}$ sensitivity, and poor retention in cells (Tsien, 1989) (our unpublished observations). Dihydrorhodaminc 123 (DHR123) may be a selective indicator for peroxynitrite (Koody et al., 1994) and recently has been used to show that neurons generate ROS (Dugan et al., 1994). DHR123 is oxidized to rhodamine 123 (R123), a dye that stains mitochondria selectively in accordance with their typically highly negative transmembrane potential (Emaus et al., 1986). R123 may not be well retained under conditions in which ROS are being generated actively, conditions in which cells and mitochondria are depolarized. 

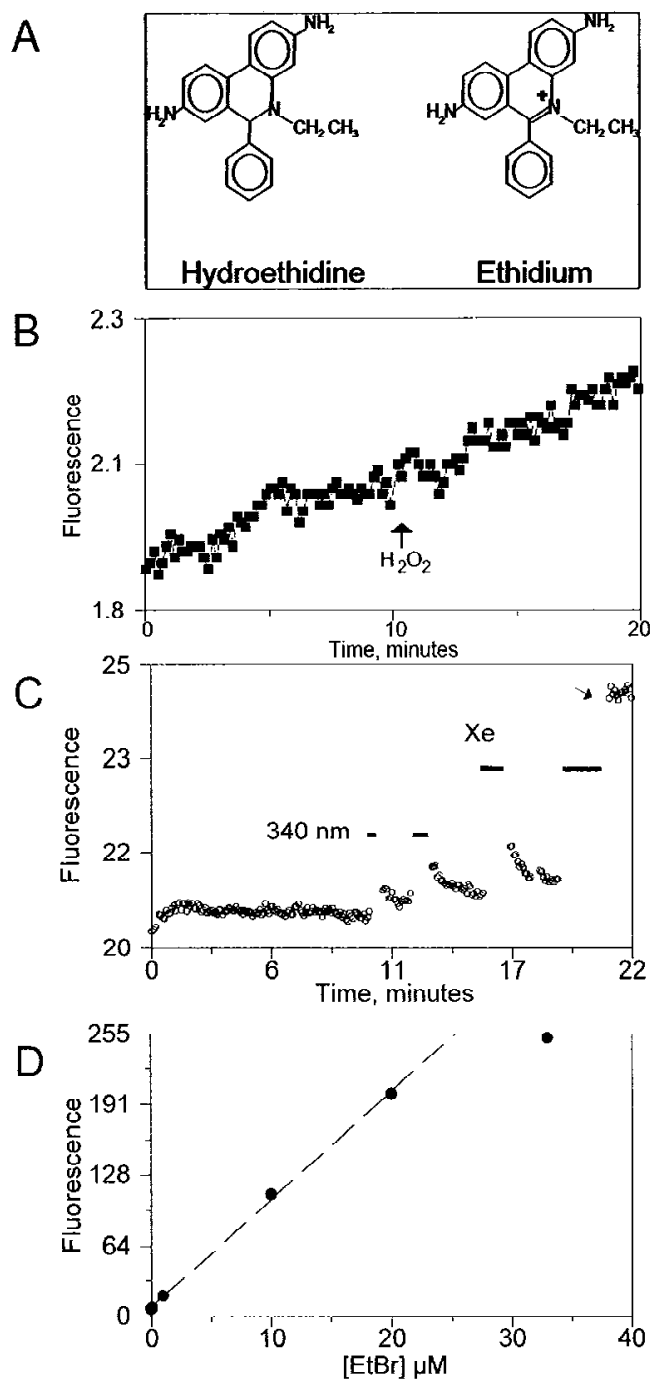

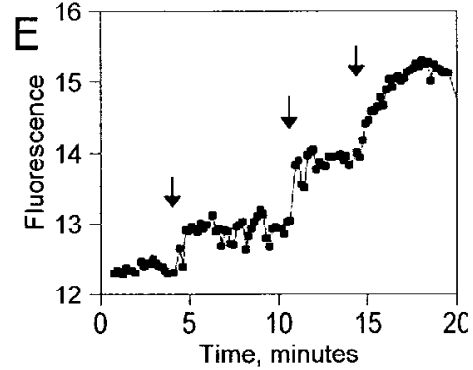

Figure 1. Fundamental properties of HFt. $A$, Structures of HEt (Ilydroethidine, left) and Et (Ethidium, right). Oxidation of HEt is accompanied by a hydrogen loss from the hetcrocyclic ring, resulting in a charged structure with red fluorescence. $B$, Auto-oxidation of HEt to Et was slow under normal data collection methods. Each data point is the mean fluorescence ( $\mathrm{Ex}=$ $510 \mathrm{~nm}, \mathrm{Em}>590 \mathrm{~nm}$ ) for images (average of 16 frames) taken every $10 \mathrm{sec}$. Here, the mean slope was $0.02 \mathrm{Fl} . \mathrm{U} / \mathrm{min}$ and was unchanged after addition of a high concentration of $\mathrm{H}_{2} \mathrm{O}_{2}$ (arrow, $\left.175 \mathrm{mM}\right)$. Note high gain of ordinate. $C$, The auto-oxidation rate also was low in the presence of $1 \mu \mathrm{g} / \mathrm{ml}$ psoralen. The $38 \mathrm{sec}$ illumination of psoralen with $340 \mathrm{~nm}$ light was expected to generate singlet $\mathrm{O}_{2}$. The resulting increase in fluorescence was small and similar to that in the absence of psoralen (data not shown). The sag in fluorescence probably was attributable to diffusion of $\mathrm{Et}$ away from the local site of UV illumination. Similar results were seen after a $54 \mathrm{sec}$ illumination with $340 \mathrm{~nm}$ UV. Larger jumps in fluorescence occurred for longer exposures $(75$ and $142 \mathrm{sec})$ to full spectrum $\mathrm{Xe}$ arc $(1.5$ ND filter). The dye appears not to be oxidized by singlet oxygen, a result confirmed by lack of effect of singlet $\mathrm{O}_{2}$ generated by $\mathrm{H}_{2} \mathrm{O}_{2}$ plus hypochlorite (data not shown). $D$, Microfluorimetry was set to give a linear response to free ethidium concentrations between 10 $\mathrm{nM}$ and $20 \mu \mathrm{M}\left(R^{2}=0.999\right)$. The fluorescencc at $30 \mu \mathrm{M}$ EtBr saturated the camera. Different optics and camera settings produced various ranges of linear response (data not shown). $E$, HEt was oxidized by $\mathrm{O}_{\urcorner}^{-}$produced by decomposition of $\mathrm{KO}_{2}$. Three applications of $\mathrm{KO}_{2}-$ saturated DMSO are indicated by arrows. Each produced a stepwise increase in Et fluorescence.
Hydroethidine (HEt) (also known as dihydroethidium) first was uscd as a redox probe by Gallop ct al. (1984). HEt is a frecly permeable, blue fluorescent dye until oxidized to the common polynucleotide stain ethidium (Et) (Fig. 1A). Gallop et al. (1984) suggested that the dye was converted enzymatically to Et in the presence of NADP ${ }^{+}$, but provided no experimental data. Subsequently, selective $\mathrm{HEt}$ oxidation by $\mathrm{O}_{2}^{-}$has been proposed (Bucana et al., 1986; Rothe and Valet, 1990). HEt has been used to study respiratory burst in immunocytes (Rothe and Valet, 1990; Perticarari et al., 1991; Shi et al., 1991) and redox state in tumor cells (Olive, 1989). The intercalation of Et into DNA and ability to be fixed into tissue (Bucana et al., 1986) made the probe an attractive candidate for studying ROS generation in neuronal tissues.

To establish the roles of specific radical species in different ccllular phenomena, it would be helpful to have selective methods for their rapid measurement in functioning cells. To this end, we have investigated the selectivity of $\mathrm{HEt}$ for $\mathrm{O}_{2}^{-}$and whether it is amenable for imaging $\mathrm{O}_{2}^{-}$production within individual neurons. Our results demonstrate the use of $\mathrm{HEt}$ as an $\mathrm{O}_{2}^{-}$indicator in various neuronal preparations and implicate mitochondria as a major source of $\mathrm{O}_{2}^{-}$production under basal conditions as well as during scveral potential disease states.

\section{MATERIALS AND METHODS}

HEt was obtained from Molecular Probes (Eugene, OR). Carbonylcyanide p-(trifluoromethoxy)phenyl hydrazone (FCCP; Sigma, St. Louis, $\mathrm{MO}$ ) was made as a $1 \mathrm{mM}$ stock in $95 \% \mathrm{EtOH}$ and diluted to $1 \mu \mathrm{M}$ final concentration in saline. $S$-nitrosocysteine (SNOC) was made as a $100 \mathrm{mM}$ stock just before use and was kept on ice until used (Lei et al., 1992). Final concentrations of 300 and $100 \mu \mathrm{m}$ were used. These concentrations did not affect the $\mathrm{pH}$ of the final solution. Sodium nitroprusside (SNP), $\mathrm{l}$-arginine ( $\mathrm{I}-\mathrm{Arg}$ ), I-nitroarginine (LNA), and $\mathrm{NaCN}(\mathrm{CN})$ (all from Sigma) were mixed in regular saline. R123 and ethidium bromide (EtBr) were obtained from Molecular Probes; $\mathrm{KO}_{2}$ was obtained from Aldrich (Milwaukee, WI).

Preparation of HEt. HEt was prepared as a $10 \mu \mathrm{g} / \mu \mathrm{l}$ stock in dry, $\mathrm{N}_{2}$-sparged dimethylsulfoxide (DMSO), packed under $\mathrm{N}_{2}$, and stored at $-80^{\circ} \mathrm{C}$. Working stocks consisted of $1 \mu \mathrm{g} / \mu \mathrm{l}$ dilutions also made in sparged DMSO and had a very pale pink color. Although sealed stocks were stable at room temperature for up to a few weeks, a fresh aliquot was used for each experiment. Stocks in open containers slowly turned dark red. Drugs and test solutions usually were made in regular saline; all solutions contained $3.2 \mu \mathrm{M}$ HEt and $0.1 \%$ DMSO $(14 \mathrm{~mm})$. Fresh working solutions were made daily. Regular $2 \mathrm{Ca}^{2+} / \mathrm{Na}$-based saline contained (in $\mathrm{mM}$ ): $\mathrm{NaCl} 144$, HEPES $10, \mathrm{CaCl}_{2} 2, \mathrm{MgCl}_{2} 1, \mathrm{KCl} 5$, and D-glucose 10 (312 mOsm, pH 7.4, adjusted with $\mathrm{NaOH})$. Saline with 50 mM KCl was madc by substituting an cquivalcnt amount of $\mathrm{NaCl}$. Salinc with $0 \mathrm{Ca}^{2+}$ was made by substituting an equivalent amount of $\mathrm{Mg}^{2+}$ and adding $100 \mu \mathrm{M}$ EGTA. Salinc with $0 \mathrm{Ca}^{2+}$ and $0 \mathrm{Mg}^{2+}$ containcd $100 \mu \mathrm{M}$ EGTA, and osmolarity was corrected with sucrose. $\mathrm{Na}^{+}$-free saline was made by substituting $N$-methyl-D-glucaminc chloride (NMDG) for $\mathrm{NaCl}$. 
Fluorescence assays. All assays were conducted on the stage of a Nikon Diaphot epiffuorescence microscope with illumination from a $150 \mathrm{~W}$ Xe arc [attenuated by a neutral density (ND) 1.5, ultraviolet (UV)-grade filter; Omega Optical, Brattleboro, VT] and through standard thodamine optics (excitation (Ex) $510-560 \mathrm{~nm}$; dichroic mirror (DM) $580 \mathrm{~nm}$; (emission) $(\mathrm{Em})>590 \mathrm{~nm})($ Nikon, Melville, NY). Most images were formed using a $40 \times$ Fluor NA 0.85 objective (Nikon) and collected on a Hamamatsu ICCD (sensitivity set at 7.0). Images were 8-bit (256 intensity levels). Typically, 16 frames were averaged every $10 \mathrm{sec}$. Background subtraction was made using the first image obtained when HEt solution was added and, in addition, from a cell-free region of the field to track subsequent changes in background. Data acquisition was controlled by Fluor or IMAGE1 software (Universal Imaging, West Chester, PA), and average intensity over $1-35$ regions of interest were logged to hard disk and displayed in real time. Linear regressions were fit to data to quantify HEt oxidation under different treatments. Slopes were compared using ANOVA and post hoc contrasts. Phase-contrast or higher-resolution fluorescence images were averaged (256 frames) to improve signal-tonoise ratio. High-magnification images were made using a Leitz $100 \times$, oil-immersion [numerical aperture (NA) 1.3] objective (Leica, Malvern, PA). All assays were conducted at room temperature $\left(20.5-22.5^{\circ} \mathrm{C}\right.$ )

The Plexiglas sample chamber contained $1 \mathrm{ml}$ of solution and consisted of a $15 \mathrm{~mm}$, \#1 coverslip (cell-free or plated with cells) forming the bottom of a well that was fit with ports for solution changes. The coverslip was held in place by high-vacuum silicone grease and stainless steel clips.

Calibration was made using EtBr as a standard. EtBr was dissolved in deionized water $(1 \mathrm{~mm})$ and diluted serially. Intensity measurements were made using the same optics and camera settings as for experiments with cultured neurons.

Cell-free assays. $\mathrm{O}_{2}^{-}$was generated using xanthine $(\mathrm{X}) / \mathrm{XO}$ in phosphate buffer at pH 7.8 (Elstner and Heupel, 1976). Other experiments used $\mathrm{XO}+\mathrm{X}$ in regular saline and without hydroxylammonium chloride (HAC). HEt oxidation was faster without $\mathrm{HAC}$. A saturated $\mathrm{KO}_{2}$ solution was made by mixing $\mathrm{KO}_{2}$ reagent in degassed DMSO and allowing excess reagent to settle out (Lokesh and Cunningham, 1986). In some experiments, dry $\mathrm{KO}_{2}$ was added directly to the observation chamber.

Singlet $\mathrm{O}_{2}$ was generated by adding $\mathrm{H}_{2} \mathrm{O}_{2}+\mathrm{NaOCl}$ to $\mathrm{HEt}$ solution. It also was generated by UV cxcitation of psoralen (cf. Halliwell and Gutteridge, 1984; Bensasson et al., 1993).

Cell culture and assay. Hippocampal pyramidal neurons were prepared from stage E17 animals as described previously (Abele et al., 1990). Cells were maintained in N2.1 serum-free medium above a layer of feeder astrocytes. For comparison, we also used secondary (replated) astrocytes grown in medium containing horse serum. Cells were rinsed twice in regular saline, transferred to the observation chamber, and treated with HEt solution. Solution changes were made by removing most of the chamber contents while adding $2.5-3 \mathrm{ml}$ of the new solution directly to the chamber. Mitochondria were stained by applying $10 \mu \mathrm{g} / \mathrm{ml}(26 \mathrm{nM}$ ) $\mathrm{R} 123$ in saline for $2 \mathrm{~min}$. Staining of the mitochondria was very bright compared with Et, camera gain was reduced, and the contribution of Et to the R123 signal was small.

Hippocampal slices and assay. Hippocampal slices wcrc obtaincd from 2- to 3-week-old rat pups. Animals were anesthetized deeply and decapitated. The brain was dissected out rapidly in ice-cold bicarbonatebuffered saline bubbled with $95 \% \mathrm{O}_{2} / 5 \% \mathrm{CO}_{2}$. Vibratome slices (150-250 $\mu \mathrm{m}$ thick) were transferred to a chamber containing oxygenated saline $\left(32^{\circ} \mathrm{C}\right)$ for $1 \mathrm{hr}$. Slices were treated with $\mathrm{HEt}$ and drugs for $20 \mathrm{~min}$ in 35 $\mathrm{mm}$ plastic culture dishes in an oxygenated chamber at room temperature. HEt and drugs were made in regular HEPES-buffered saline and bubbled with medical-grade $\mathrm{O}_{2}$. Slices then were fixed in $4 \%$ paraformaldehyde and imaged using a $4 \times$ NA 0.12 fluorescence objective (Leitz) or a $10 \times$ NA 0.5 Fluor objective (Nikon). Shading correction was made using a reference image of $100 \mu \mathrm{M}$ EtBr solution. Average fluorescence intensity of the slices was calculated using IMAGE1 software. Intensities were compared using ANOVA and Dunn contrasts.

\section{RESULTS}

\section{Basic properties of HEt and Et}

HEt is a cell-permeant, blue-fluorescent compound (Excita-

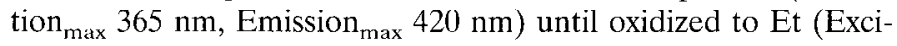

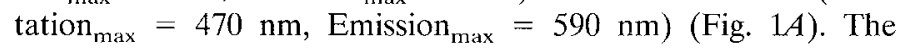
reduced as well as oxidized compounds exhibit good photostability under normal illumination conditions (Fig. 1B) [auto-oxidation rate in this example was 0.2 fluorescence intensity unit (Fl.U)/ min]. This rate was not increased by the addition of $175 \mathrm{mM} \mathrm{H}_{2} \mathrm{O}_{2}$ (Fig. $1 B$ ). However, photoconversion of $\mathrm{HEt}$ to $\mathrm{Et}$ by shortwavelength illumination has been reported (Swannell et al., 1992). Brief illuminations at $340 \mathrm{~nm}$ caused small stepwise increases in fluorescence (Fig. 1C), and long exposures to full-spectrum UV illumination produced larger increases (arrow). The photoconversion was enhanced neither by psoralen, a generator of singlet $\mathrm{O}_{2}$ (Halliwell and Gutteridge, 1984; Bensasson et al., 1993), nor by singlet $\mathrm{O}_{2}$ generated with hypochlorite $+\mathrm{H}_{2} \mathrm{O}_{2}$ (Bensasson et al., 1993) (data not shown). Although HEt displayed some propensity for photoconversion, it was more stable than DCFH or DHR123 (slopes 10-fold greater under similar conditions; data not shown).

The imaging system under standardized settings was able to detect free. Et as low as $10 \mathrm{~nm}$ and gave a linear response up to 20 $\mu \mathrm{M}$ Et $\left(R^{2}=0.999\right.$; Fig. $\left.1 D\right)$. Under standard conditions, each arbitrary Fl.U corresponded to $\sim 100 \mathrm{nmol}$ of free Et. The binding of Et to polynucleotides also increases the quantum efficiency by $\sim 20$-fold (LePecq and Paoletti, 1967). This property, along with the nonratiometric nature of the HEt, complicates quantitation within intact cells and results in semiquantitative estimates of $\mathrm{O}_{2}^{-}$ production.

\section{HEt is oxidized by $\mathrm{O}_{2}^{-}$}

As reported previously (Rothe and Valet, 1990; Carter et al., 1994), HEt is oxidized to Et by $\mathrm{O}_{2}^{-} . \mathrm{KO}_{2}$-saturated DMSO produces a burst of $\mathrm{O}_{2}^{-}$when added to aqueous solutions (Lokesh and Cunningham, 1986). The addition of $\mathrm{KO}_{2}$ solution (Fig. $1 E$, arrows) to a solution containing $1 \mu \mathrm{g} / \mathrm{ml} \mathrm{HEt}(3.2 \mu \mathrm{M})$ caused a stepwise increase in fluorescence consistent with the oxidation of $\mathrm{HEt}$ to Et. Addition of very high concentrations of dry $\mathrm{KO}_{2}$ reagent resulted in loss of fluorescence, suggesting that Et could be oxidized further to nonfluorescent forms under extreme conditions (data not shown).

We also generated $\mathrm{O}_{2}^{-}$enzymatically using $\mathrm{X} / \mathrm{XO}$ (Fig. 2, $X O+X)$. In the experiment shown in Figure $2 A$, the autooxidation rate in $X(\sim 0.5 \mathrm{Fl} . \mathrm{U} / \mathrm{min})$ was increased to $4.1 \pm 0.4$ Fl.U/min after the addition of $\mathrm{XO}\left(52 \mathrm{mU} / \mathrm{ml}\right.$ ) (expected $\mathrm{O}_{2}^{-}$ generation of $52 \mathrm{nmol} \cdot \mathrm{min}^{-1} \cdot \mathrm{ml}^{-1}$ ). The initial increase in $\mathrm{Et}$ fluorescence was linear, or nearly so. The addition of $\mathrm{Cu} / \mathrm{Zn}-\mathrm{SOD}$ $(9 \mathrm{U} / \mathrm{ml})$ to the reaction mixture produced an oxidation rate not significantly different from $\mathrm{XO}$ alone $(0.83 \pm 0.02 \mathrm{Fl} . \mathrm{U} / \mathrm{min} ; p=$ 0.2 ). The $\mathrm{X} / \mathrm{XO}$ reaction also is known to produce $\mathrm{OH}$ (Kuppusamy and Zweier, 1989). The assay conditions use a 4300 -fold excess of DMSO (a very efficient $\cdot \mathrm{OH}$ scavenger) (Traystman et al., 1991; Scaduto, 1995) over HEt. Under these conditions, $\cdot \mathrm{OH}$ radicals most likely will be scavenged by DMSO before reacting with HEt. Additional evidence is the lack of HEt oxidation by Fe/ascorbate/ $\mathrm{H}_{2} \mathrm{O}_{2}$ (Fig. $2 B$ ). $\mathrm{H}_{2} \mathrm{O}_{2}$ and iron-catalyzed $\cdot \mathrm{OH}$ production was not able to convert HEt to Et under assay conditions. -OH sensitivity was observed when dimethylformamide (not a -OH scavenger) was used as the solvent for HEt (data not shown).

We tested agents later used to characterize neuronal $\mathrm{O}_{2}^{-}$production for possible interactions with the HEt assay. In the presence of ascorbate, SNP generates NO radicals (Feelisch, 1991; Lipton and Stamler, 1994), which by themselves are unable to oxidize HEt (Fig. $2 B$ ) but do inhibit the X/XO-mediated oxidation HEt. It is likely that the inhibitory action was attributable to the formation of peroxynitrite by the rapid reaction of $\mathrm{NO}$ with $\mathrm{O}_{2}^{-}$ (reaction rate $=6.7 \times 10^{9} \mathrm{M}^{-1} \cdot \mathrm{s}^{-1}$ ) (Huie and Padmaja, 1993) that apparently out-competed the oxidation of IIEt by $\mathrm{O}_{2}^{-}$. The ineffectiveness of peroxynitrite itself (actually peroxynitrous acid 
A

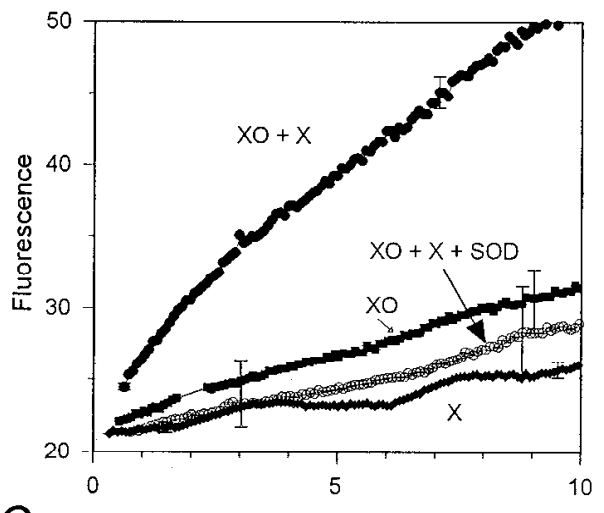

$\mathrm{C}$

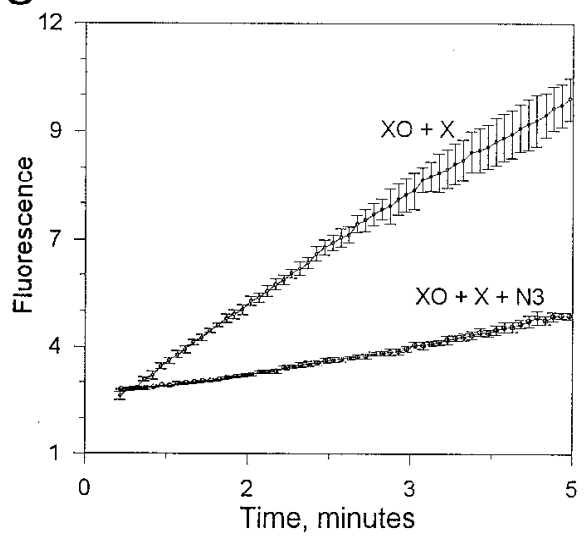

$B$
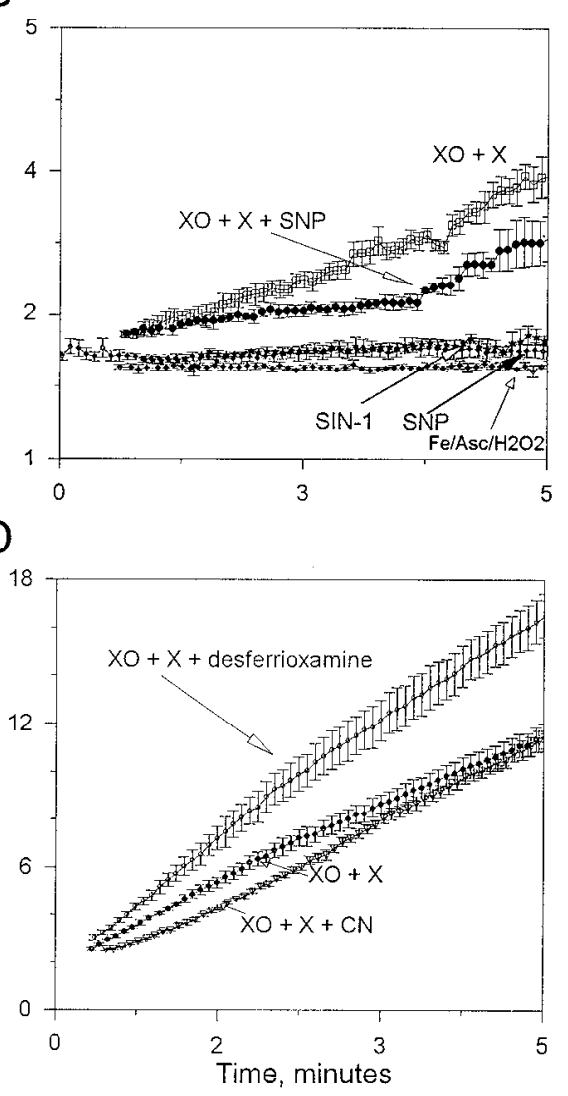

Figure 2. Cell-free oxidation assays. $A$, The rate of HEt oxidation was enhanced by the action of $\mathrm{X}$ and $\mathrm{XO}$ in a cell-free system. The rate observed for HEt plus $1.9 \mathrm{~mm} X$ (initial slope $=$ $0.48 \pm 0.11 \mathrm{Fl} . \mathrm{U} / \mathrm{min}$ ) was similar to autooxidation of HEt. Initial rates of $\mathrm{HEt}$ oxidation were slightly higher in the presence of $3 \mathrm{mU}$ of $X O(1.2 \pm 0.4 \mathrm{Fl} . \mathrm{U} / \mathrm{min})$. This may indicate that HEt was a weak substrate for $\mathrm{XO}$, similar to the case reported for $2^{\prime}, 7^{\prime}$-DCFH (Zhu et al., 1994). Dye conversion in the presence of $X O+X$ was significantly faster $(4.1 \pm 0.4 \mathrm{Fl} . \mathrm{U} / \mathrm{min})$ than for either component alonc. Addition of excess SOD (9 U/ml; curve $X O+X+S O D)$ produced a rate of rise $(0.84 \pm 0.02 \mathrm{Fl} . \mathrm{U} / \mathrm{min})$ similar to $\mathrm{XO}$ alone $(p=0.2)$. Data are the mean \pm SEM of three replicates. Only one SEM bar is shown per trace to decrease clutter. $B$, HEt was not oxidized by nitrogen radicals or $\cdot \mathrm{OH}$. $S N P(1 \mathrm{mM})$ did not support oxidation of HEt (rate $=0.02 \pm$ $0.01 \mathrm{FI} . \mathrm{U} / \mathrm{min} ; n=3$ ). A similar result was obtained with SNOC $(300 \mu \mathrm{M}$; rate $=0.04 \pm 0.01$ Fl.U/min) (data not shown). HEt oxidation did not occur in $\mathrm{H}_{2} \mathrm{O}_{2}$ (176 $\left.\mathrm{mm}\right)$ plus $\mathrm{Fe}\left(\mathrm{NH}_{4}\right)_{2}\left(\mathrm{SO}_{4}\right)_{2}(30 \mu \mathrm{M})$ and ascorbic acid (30 $\mu \mathrm{M}$; rate $=0.02 \pm 0.01 \mathrm{Fl} . \mathrm{U} / \mathrm{min})$, conditions that favored gencration of OII. $X O+X$ produced a mean rate of $0.7 \pm 0.01 \mathrm{Fl} . \mathrm{U} / \mathrm{min}(n=$ 3 ). This was reduced to $0.14 \pm 0.02 \mathrm{Fl} . \mathrm{U} / \mathrm{min}$ by the addition of $1 \mathrm{mM} \mathrm{SNP.} \mathrm{SIN-1} \mathrm{generates} \mathrm{both}$ $\mathrm{O}_{2}^{-}$and $\mathrm{NO}$, thus forming peroxynitrite. SIN-1 $(1 \mathrm{mM})$ produced a low rate of $\mathrm{HEt}$ oxidation $(0.13 \pm 0.04 \mathrm{Fl} . \mathrm{U} / \mathrm{min})$, possibly because of $\mathrm{O}_{2}^{-}$ that escaped peroxynitrite formation. $C$, Oxidation of $\mathrm{HEt}$ by $\mathrm{O}_{2}^{-}$was reduced by $53 \%$ with the addition of $3 \mathrm{~mm} \mathrm{NaN}(X O+X$ rate $=1.2 \pm$ $0.6, X O+X+N_{3}=0.6 \pm 0.4 \mathrm{Fl} . \mathrm{U} / \mathrm{min} ; n=3$ and 4 , respectively). This inhibition may have been attributable to NO generation by $\mathrm{N}_{3}$ and loss of $\mathrm{O}_{2}^{-}$to peroxynitrite. $D$, Cyanide $(3 \mathrm{mM})$ did not affect $\mathrm{X} / \mathrm{XO}$-mediated $\mathrm{HEt}$ oxidation $(X O+X$ rate $=1.6 \pm 0.07, X O+X+C N$ rate $=1.7 \pm 0.1 \mathrm{Fl} . \mathrm{U} / \mathrm{min} ; n=4 ; p>0.05$ ). Addition of the iron chelator desferrioxamine $(10 \mu \mathrm{M})$ increased the oxidation rate significantly $(2.4 \pm 0.1$ Fl.U/min; $p<0.05$ ), suggesting that $\mathrm{O}_{2}^{-}$was consumed by trace iron present in solutions. at assay $\mathrm{pH}$ ) in oxidizing HEt also was shown by the low oxidation rate in the presence of 3-morpholinosydnonimine [Fig. $2 B, S I N-1$ ( $1 \mathrm{~mm}$ )], a compound that generates both $\mathrm{O}_{2}^{-}$and NO (Feelisch et al., 1989; Hogg et al., 1992). The inhibitory effects of NO on $\mathrm{X} / \mathrm{XO}$-mediated HEt oxidation also were observed in the presence of SNOC ( $300 \mu \mathrm{m}$; data not shown). The oxidation was not inhibited by equivalent concentrations of L-cysteine/ $\mathrm{HCl}$ (L-cys; data not shown) (see also Fig. $6 D, E$ ). The X/XO oxidation of HEt was reduced significantly $(53 \%, p<0.001)$ by $\mathrm{NaN}_{3}(3 \mathrm{~mm}$; Fig. $2 C$ ). Although $\mathrm{N}_{3}$ is a scavenger of singlet $\mathrm{O}_{2}$ (Bensasson et al., 1993), the inhibitory action may be attributable to the ability of azide to generate NO (Smith and Wilcox, 1994), shown in Figure $2 B$ to out-compete $\mathrm{HEt}$ for $\mathrm{O}_{2}^{-}$. It is unlikely that the lower oxidation rate was attributable to $\mathrm{N}_{3}$ scavenging singlet $\mathrm{O}_{2}$, because singlet $\mathrm{O}_{2}$ was unable to oxidize $\mathrm{HEt}$ under our assay conditions (see above and Fig. 1). Cyanide (3 mM) did not affect $\mathrm{X} / \mathrm{XO}$-mediated HEt oxidation (Fig. $2 \mathrm{D}$ ), but the addition of desferrioxamine $(10 \mu \mathrm{M})$, an iron chelator, significantly increased the initial rate 1.5 -fold $(p<0.05$; Fig. $2 D$ ). A possible explandion for this is that chelation of trace iron contaminants may have prolonged the lifetime of $\mathrm{O}_{2}^{-}$by eliminating Fenton-like reactions, protecting the enzyme, thus preserving a higher $\mathrm{O}_{2}^{-}$concentra- tion. L-Arg and LNA did not affect the rate of HEt oxidation by $\mathrm{X} / \mathrm{XO}$ (data not shown).

\section{$\mathrm{O}_{2}^{-}$generation in cultured rat neurons and glia}

When neurons were incubated in saline containing HEt, the basal rate of fluorescence increase was much higher than that observed in cell-free assays (Fig. 3B). Oxidation rates higher than autooxidation were observed in numerous types of rat neurons including cerebellar Purkinje neurons and superior cervical ganglion sympathetic neurons, as well as in secondary cortical astrocytes, PC12 cells, and endothelial cells (data not shown). The initial sites of Et fluorescence were nonuniform, mostly evident in the soma (Fig. $3 A$ ), but also prominent within the neurites (see Fig. 3A,C). The punctate Et fluorescence was colocalized with mitochondria when subsequently stained with R123, although not all mitochondria had detectable Et fluorescence (Fig. $3 C$ ). This suggested that mitochondria were one source of $\mathrm{O}_{2}^{-}$. If HEt was washed out, then the bright punctata appeared to destain rapidly, suggesting that the bright regions were sites of Et generation rather than its sequestration. The apparent staining of only a subset of mitochondria suggested further that Et was not accumulated within mitochondria much like other cationic dyes like R123. Application of 

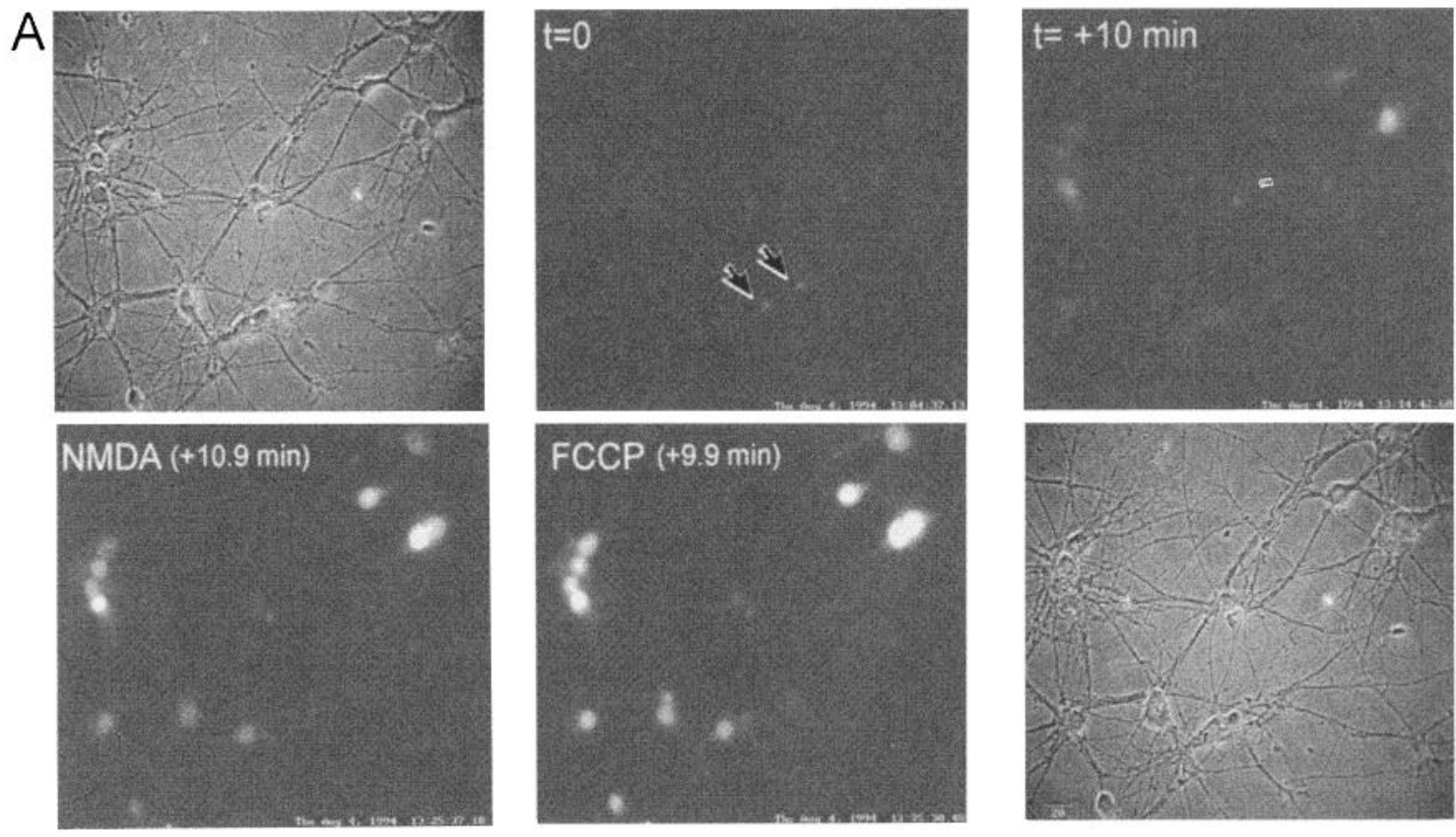

$\mathrm{B}$

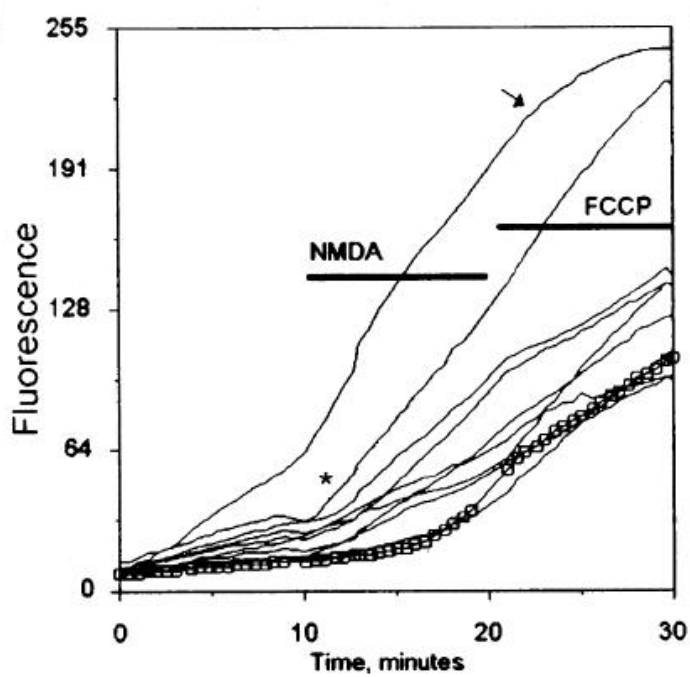

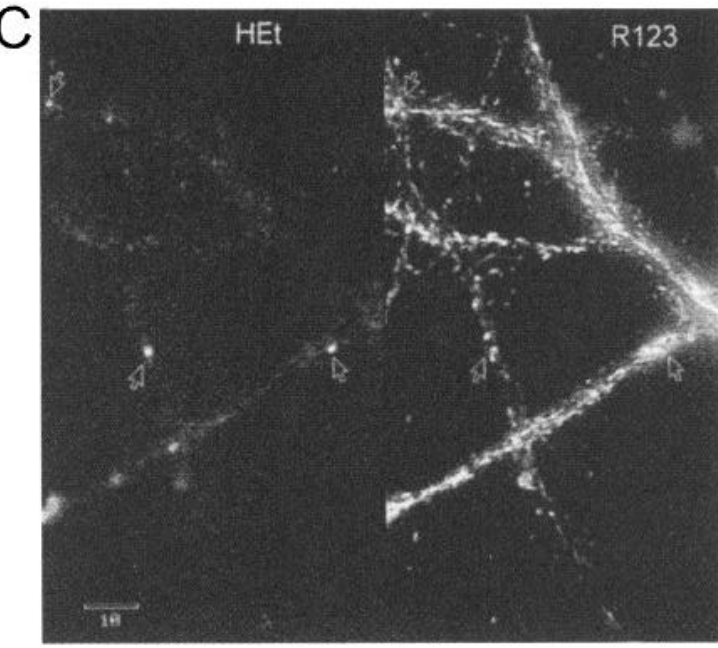

Figure 3. Responses of hippocampal neurons. $A$, Incubation of hippocampal neurons ( $11 \mathrm{~d}$ in vitro) with HEt (3.2 $\mu \mathrm{M})$ produced an increase in fluorescence first evident in cell somas. The initial staining of nuclei of dead cells (arrows) evident at time $0(t=0)$ occurred as a result of Et formed by auto-oxidition of HEt solution. Mean fluorescence intensity was determined by setting regions of interest over the somas (in phase-contrast image) and after subtraction of the fluorescence image at time $=0$. At time $=+10 \mathrm{~min}(t=+10 \mathrm{~min})$, cells were stained to different extents. The amount and rate $(\mathrm{see} B$ ) of HEt oxidation increased after $10.9 \mathrm{~min}$ of treatment with $30 \mu \mathrm{M} \mathrm{NMDA}[N M D A(+10.9 \min )]$ (in $0 \mathrm{Mg}$ saline $+10 \mu \mathrm{M}$ glycine), and after $1 \mu \mathrm{M}$ $F C C P$. Cells appeared swollen after these treatments. All fluorescence panels have been gamma-corrected digitally by a constant to aid illustration of faintly stained structures. The width of each panel originally was $324 \mu \mathrm{m}$. B, Continuous record of fluorescence for neuronal somas for cells shown in $A$. The increase in $\mathrm{O}_{2}^{-}$production was delayed to varying degrees ranging from nearly immediate (curve *) to 7 min after application (open squares). $\mathrm{O}_{2}^{-}$ production, on average, was not increased additionally by $F C C P$. This implies that mitochondria were fully depolarized by the $N M D A$ treatment. Signal from one neuron approaches camera saturation (arrow). C. High-magnification image of initial Et staining pattern revealed distinct punctata (arrows). Left image was taken $\sim 3 \mathrm{~min}$ after application of $H E t$ solution. Right image pair was taken after 2 min staining with $10 \mu \mathrm{g} / \mathrm{ml}(26 \mathrm{~nm}) R 123$ and at lower camera gain. Numerous brightly stained mitochondria are evident, and some were colocalized with Et-stained regions (arrows). Thus, all Et-stained regions colocalized with mitochondria, but the converse was not true. Scale bar, $10 \mu \mathrm{M}$.

the glutamate receptor agonist NMDA $(100 \mu \mathrm{M})$ increased the rate of $\mathrm{O}_{2}^{-}$production in most neurons (Fig. 3A). The bulk of the Et was in the soma consistent with the bulk of the R123-stained mitochondria located there (the nucleus later becoming brightly stained, especially the nucleolus), but also was present in dendritic swellings that formed during NMDA exposure. Other glutamate receptor agonists also increased $\mathrm{O}_{2}^{-}$production (see below). Application of FCCP $(1 \mu \mathrm{M})$ uncoupled mitochondria and increased the rate of HEt oxidation (see below), but did not increase the rate of $\mathrm{O}_{2}^{-}$production over that produced by a robust NMDA response (Fig. $3 A, B$ ). FCCP did not increase the rate of $\mathrm{HEt}$ auto-oxidation in cell-free assays $(n=4)$. This again suggested that mitochondria were a major source of $\mathrm{O}_{2}^{-}$. Quantitation of $\mathrm{O}_{2}^{-}$ production in this example is shown in Figure $3 B$. The mean basal rate of $\mathrm{O}_{2}^{-}$production in hippocampal neurons varied over a wide range (e.g., range $0.6-2.6 \mathrm{Fl} . \mathrm{U} / \mathrm{min}$ for 9 DIV neurons, $n=8$ preparations; in this example, $n=11$ cells, 11 DIV, range $0.23-$ 10.7 Fl.U/min, mean $=2.7 \pm 0.8 \mathrm{Fl} . \mathrm{U} / \mathrm{min})$. Neurons in poor 


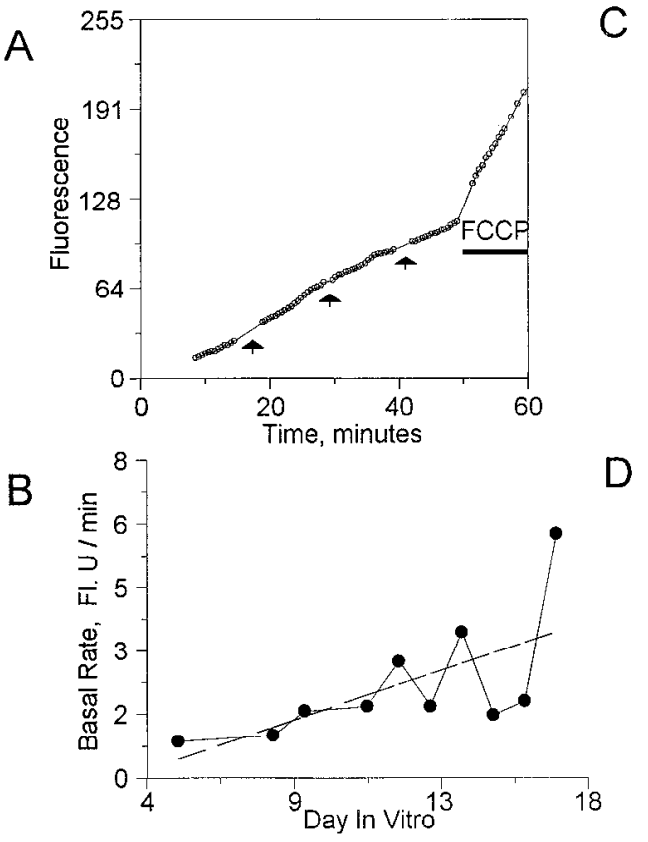

Figure 4. Cultured neurons produce linear rates of rise under basal conditions. $A$, Long control record of increase in $\mathrm{Et}$ fluorescence remained constant until cells were challenged with $F C C P$ $(1 \mu \mathrm{M})$. HEt solution was replaced with fresh saline as indicated by arrows. Trace is the average of five neurons. $B$, Basal rate of HEt oxidation tended to increase with age in cultured hippocampal neurons. The dotted line is a linear regression (linearity, $p=0.01 ; R^{2}=0.42$ ) fit to mean rate per DIV $(n=1-8$ experiments per DIV). $C$, Basal rate usually was not increased by application of $50 \mathrm{~K}$. Basal rate is shown by the dashed line. In some cells, the rate was lower during $50 \mathrm{~K}$ application (see Fig. 5D and Results). The HEt oxidation rate increased during application of saline with $0 \mathrm{mM}$ $\mathrm{Mg}^{2+}(O \mathrm{Mg})$, perhaps because of augmentation of NMDA ionophore activity. $D$, Mean basal rate increased 3.1-fold after application of $K A(200 \mu \mathrm{M})$ (basal rate $=1.8 \pm 0.02 ; \mathrm{KA}$ rate $=5.5 \pm 0.07$ $\mathrm{Fl} . \mathrm{U} / \mathrm{min} ; n=11$ ). health (i.e., those possessing vacuoles, granular cytoplasm, beaded neurites) had especially high "basal" rates (data not shown). Rates of HEt oxidation typically were lower in glial cells in which FCCP treatment also often failed to increase rates. The rates in neurons increased $\sim 2.5$-fold during NMDA treatment $(6.8 \pm 1.1 \mathrm{Fl} . \mathrm{U} /$ min; Fig. 3) with a time lag ranging from nearly immediate onset (asterisk indicates curve) to delays of up to $7 \mathrm{~min}$ in the example shown (open squares). $\mathrm{O}_{2}^{-}$production could be monitored under standard conditions until the Et fluorescence intensity saturated the camera (intensity - 255 - background). One such cell is seen in this example (Fig. $3 B$, arrow). The mean rate of rise on subsequent FCCP treatment was similar $(6.6 \pm 0.8 \mathrm{Fl} . \mathrm{U} / \mathrm{min})$ to that in NMDA, suggesting that the mitochondria already were fully uncoupled by the NMDA treatment. Exceptions to this were observed in immature ( $\leq 8$ DIV) hippocampal neurons that lacked substantial NMDA currents (our unpublished observations) or in cells that lacked NMDA receptors (data not shown). FCCP usually doubled $\mathrm{O}_{2}^{-}$production in these cases (data not shown).

The basal rate of $\mathrm{O}_{2}^{-}$production remained constant over -50 min of observation (Fig. $4 A$ ). Fresh $\mathrm{HEt}$ saline was added as indicated (arrows) as a control for bath exchanges. Application of FCCP increased the rate of $\mathrm{O}_{2}^{-}$production by 2 .2-fold $(n=6$ neurons) over the basal rate in this example. This increase was not caused by a direct catalysis of HEt oxidation by FCCP (data not shown).

The basal rate of $\mathrm{O}_{2}^{-}$production also varied with the age of the cultured neurons (Fig. $4 B$ ). The rate increased by $\sim 0.3$ Fl. I $\cdot \min ^{-1} \cdot \mathrm{d}^{-1}$ in culture for neurons cultured 5-24 $\mathrm{d}\left(R^{2}\right.$ for linear regression $0.42 ; p=0.008$ ). The main source of variability was primarily associated with different cell preparations rather than between samples within a preparation.

\section{Properties of $\mathrm{O}_{2}^{-}$production in rat hippocampal pyramidal neurons}

We further investigated which treatments increased $\mathrm{O}_{2}^{-}$production in cultured hippocampal pyramidal neurons. Depolarization with $50 \mathrm{~mm} \mathrm{~K}^{+}(50 \mathrm{~K})$ saline did not increase the basal rate in 68 of 69 cells. An example is shown in Figure $4 C$. In 30 of 69 cells, however, the rate of $\mathrm{O}_{2}^{-}$production during application of $50 \mathrm{~K}$ decreased slightly (mean $=56 \%$ of basal rate; Fig. $6 B$ ). 'This decrease may have been attributable to swelling of the soma. We did obscrve an incrcase in $\mathrm{O}_{2}^{-}$production, however, if $50 \mathrm{~K}$ was applied in $\mathrm{Na}^{+}$-free saline (data not shown). This may have occurred because of elimination of swelling and/or $\mathrm{Na}-\mathrm{Ca}$ exchange and the resultant higher intracellular $\mathrm{Ca}^{2+}$ concentration $\left(\left[\mathrm{Ca}^{2+}\right]_{\mathrm{i}}\right)$ attained (see below). As shown in Figure $4 C$, enhancement of endogenous electrical activity by removal of extracellular $\mathrm{Mg}^{2+}$ increased the rate of $\mathrm{O}_{2}^{-}$production, probably via action on NMDA receptors (Abele et al., 1990). $\mathrm{O}_{2}^{-}$production was increased by concentrations of kainic acid (KA; $200 \mu \mathrm{M}$ ) expected to activate both AMPA and KA receptors (Fig. 4D). Trcatment with AMPA $(10 \mu \mathrm{M})$ also increased the rate of $\mathrm{O}_{2}^{--}$production (data not shown).

The increase in $\mathrm{O}_{2}^{-}$production by glutamate receptor agonists appeared to require entry of $\mathrm{Ca}^{2+}$, because both KA and NMDA failed to greatly increase the slope $(p>0.05$, repeated-measures ANOVA) when applied in $\mathrm{Ca}^{2+}$-free saline (Fig. $5 A, B$ ). The occasional slight increase in slope may be an indication that intracellular $\mathrm{Ca}^{2+}$ sources may be involved or that $\mathrm{O}_{2}^{-}$production also can occur by $\left[\mathrm{Ca}^{2+}\right]_{\mathrm{i}}$-independent mechanisms. Note that the slope increased abruptly on return to regular $\mathrm{Ca}^{2+}$-containing saline for both KA and NMDA $(p<0.05)$. Increased $\mathrm{O}_{2}^{-}$production by KA and NMDA was suppressed by treatment with $\mathrm{CN}^{-}(3 \mathrm{~mm}$; Fig. $5 A, B)$. Inhibition was complete in most cells but was partial in others (see Fig. $5 A$ ).

$\mathrm{CN}$ was effective in completely blocking the basal production of $\mathrm{O}_{2}^{-}$(Fig. $5 \mathrm{C}$ ). Azide ( $3 \mathrm{~mm}$ ) also was able to suppress the basal $\mathrm{O}_{2}^{-}$production (data not shown), but it is uncertain whether this action was attributable to mitochondrial inhibition and/or its ability to produce NO (see above). It should be noted that both agents inhibit Cu/Zn-SOD (Iqbal and Whitney, 1991; Smith and Wilcox, 1994), an action that actually would be expected to raise $\mathrm{O}_{2}^{-}$levels. Oligomycin did not alter the rate of $\mathrm{O}_{2}^{-}$production (data not shown). Surprisingly, FCCP was able to rescue $\mathrm{O}_{2}^{-}$ production in $\mathrm{CN}$-treated neurons (Fig. 5C, arrow). Because basal $\mathrm{O}_{2}^{-}$production was entirely sensitive to mitochondrial poisons, the main source of basal $\mathrm{O}_{2}^{-}$appeared to be the respiratory chain. 
Figure 5. The increase in $\mathrm{O}_{2}^{-}$production has a $\mathrm{Ca}^{2+}$ requirement and is sensitive to mitochondrial state. $A, K A(200$ $\mu \mathrm{M})$ failed to increase $\mathrm{O}_{2}^{--}$production in $\mathrm{Ca}^{2+}$-free saline. A break in slope $(\mathrm{ar}$ row) was produced on return to normal saline during continuous KA application. The mean basal rate was $0.7 \pm 0.02,0.7$ $\pm 0.15 \mathrm{in} \mathrm{Ca}^{2+}$-free saline, $1.1 \pm 0.15$ in $0 \mathrm{Ca} / \mathrm{KA}$, and $2.5 \pm 0.15 \mathrm{Fl} . \mathrm{U} / \mathrm{min}$ in normal saline + KA ( $n=5$ neurons). Cyanide $(3 \mathrm{~mm})$ blocked this rate increase $(C N+\mathrm{KA}$ rate $=0.7 \pm 0.25 \mathrm{Fl} . \mathrm{U} /$ min). The degree of suppression of $\mathrm{O}_{2}^{-}$ production by $\mathrm{CN}$ ranged from complete to partial (data not shown). $B, N M D A$ also increased the rate of $\mathrm{O}_{2}^{-}$production in a $\mathrm{Ca}^{2+}$-sensitive manner. Mean basal rate $(n=11)$ was $1.1 \pm 0.03$, and rate in $\mathrm{Ca}^{2+} / \mathrm{Mg}^{2+}$-free saline $(O C a, O M g)$ was $1.9 \pm 0.06,2.5 \pm 0.12$ after addition of NMDA $(300 \mu \mathrm{M})$ and doubled on return to NMDA in normal saline $(5.9 \pm 0.11$ Fl.U/min). $C N$ blocked the NMDAmediated increase in rate (slope $=1.3 \pm$ $0.11 \mathrm{Fl} . \mathrm{U} / \mathrm{min}$ ). $C$, The major source of $\mathrm{O}_{2}^{-}$is sensitive to mitochondrial state. Basal HEt oxidation was blocked by $C N$ (3 mM) and was restored by $F C C P(1 \mu \mathrm{M})$ (arrow). Removal of $\mathrm{CN}$ may not have been complete during the final $6 \mathrm{~min}$ of the experiment. $D$, Application of the $\mathrm{Ca}^{2+}$ ionophore 4-Br-A23187 (8 $\left.\mu \mathrm{M}\right)$ failed to elicit a large change in $\mathrm{O}_{2}^{-}$production. A small departure from the basal slope $(1.49 \pm 0.51 \mathrm{Fl} . \mathrm{U} / \mathrm{min})($ dotted line) is evident at the end of $5 \mathrm{~min}$ in this example (mean slope $=2.2 \pm 0.5$ Fl.U/min; $n=7)$. NMDA $(300 \mu \mathrm{M})$ increased the slope 2.9 -fold to $6.42 \pm 1.9$ Fl.U/min. $E$, The enhancement of $\mathrm{O}_{2}$ production by different treatments was nonadditive. This example shows that the rate of $\mathrm{O}_{2}^{-}$production was saturable and equivalent for stimulation by $F C C P$ and $\mathrm{H}_{2} \mathrm{O}_{2}\left(\mathrm{H} 2 \mathrm{O} 2\right.$ ), $F, K A$ applied in $\mathrm{Na}^{+}$-free saline $(N M D G)$ increased $\mathrm{O}_{2}^{-}$production. Fluorescence continued to increase on return to regular saline; however, the rate of rise slowed after $5 \mathrm{~min}$, perhaps because of swelling of the cells. Rates resumed on final return to $\mathrm{Na}^{+}$-free saline. Data are the mean of five neurons. NMDA had similar effects (data not shown).
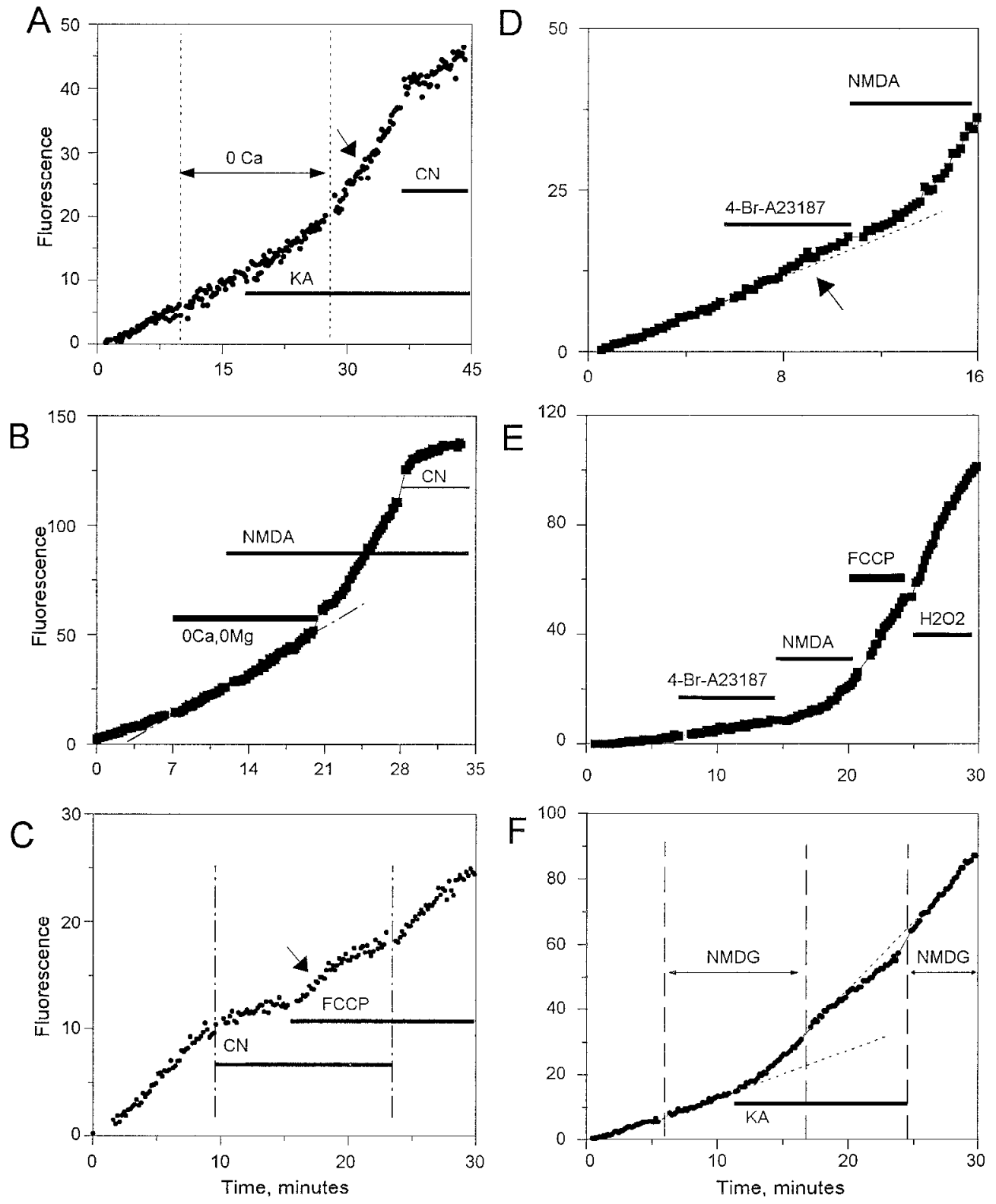

We investigated further the ionic dependence of $\mathrm{O}_{2}^{-}$produc-

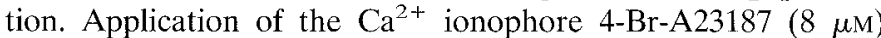
increased $\left[\mathrm{Ca}^{2+}\right]_{\mathrm{i}}$ (cf. Prehn et al., 1994), but failed to elicit a large change in $\mathrm{O}_{2}^{-}$production (Fig. $5 D, E$ ). Only a small increase over the basal slope (Fig. 5D, dotted line) was evident at the end of 5 $\min$ (slopes $=2.0 \pm 0.5$ vs $1.5 \pm 0.5 \mathrm{Fl} . \mathrm{U} / \mathrm{min} ; n=7 ; p>0.05$, repeated-measures $\Lambda$ NOV $\Lambda$ ) in this example. In the same example, NMDA $(300 \mu \mathrm{M})$ increased the slope threefold to $6.3 \pm 1.9$ Fl.U/min (significantly greater than basal, $p<0.05$ ). A similar result is seen in Figure $5 E$. In addition, the slope increase produced by NMDA was not enhanced further by FCCP or $\mathrm{H}_{2} \mathrm{O}_{2}$. $\mathrm{Na}^{+}$entry via glutamate-gated ionophores appeared unnecessary for the increase in $\mathrm{O}_{2}^{-}$production as shown for $\mathrm{KA}$ application in $\mathrm{Na}^{+}$-free saline (Fig. 5F). Similarly, application of NMDA in $\mathrm{Na}^{+}$-free saline increased $\mathrm{O}_{2}^{-}$production (data not shown).
The rate of $\mathrm{O}_{2}^{-}$production was saturable and equivalent for NMDA, FCCP, and $\mathrm{H}_{2} \mathrm{O}_{2}$ in some neurons (Fig. 5E). In other cases, FCCP failed to produce a large rise in slope in some cells, especially type 1 astrocytes (data not shown). When applied first, $\mathrm{H}_{2} \mathrm{O}_{2}$ always increased $\mathrm{O}_{2}^{-}$production. $\mathrm{CN}^{-}$blocked the $\mathrm{H}_{2} \mathrm{O}_{2}$ stimulation partially, the rate reverting to one resembling the initial basal level (Fig. 6A). One of the possible mechanisms of the $\mathrm{H}_{2} \mathrm{O}_{2}$ increase was by its block of $\mathrm{Cu} / \mathrm{Zn}$-SOD. In support of this hypothesis, $\mathrm{Cu}^{2+}$-preferring metal chelators that inactivated SOD also increased HEt oxidation. Application of ammonium 1-pyrrolidinecarbodithioate (APDC; $10 \mathrm{~mm}$ ) significantly increased the slope 4.4-fold above basal (basal $=0.45 \pm 0.04$ vs 1.98 $\pm 0.15 \mathrm{Fl} . \mathrm{U} / \mathrm{min}$ in APDC; $n=69 ; p<0.05)$, and was not significantly increased further by $\mathrm{H}_{2} \mathrm{O}_{2}\left(\mathrm{H}_{2} \mathrm{O}_{2}\right.$ rate $=2.63 \pm 0.22$ Fl.U/min; $p>0.05$, Friedman repeated-measures ANOVA/Stu- 

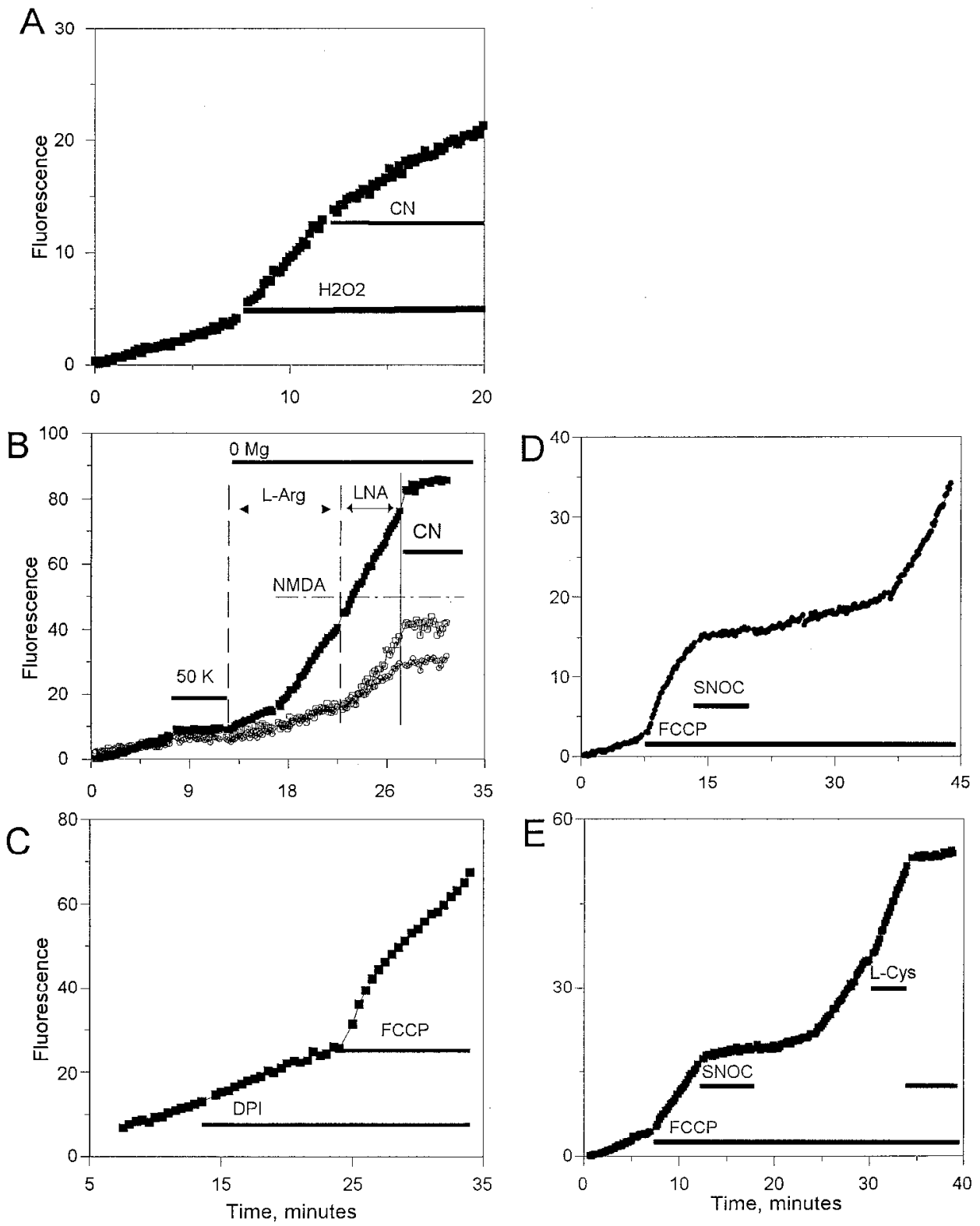

Figure 6. $A, \mathrm{H}_{2} \mathrm{O}_{2}$ produced an apparent increase in $\mathrm{O}_{2}^{-}$production by a $\mathrm{CN}$-sensitive mechanism. The base rate $(0.67+0.08$ $\mathrm{Fl} . \mathrm{U} / \mathrm{min}$ ) increased to $2.29 \pm 0.22 \mathrm{Fl} . \mathrm{U} / \mathrm{min}$ in the presence of $\mathrm{H}_{2} \mathrm{O}_{2}(\mathrm{H} 2 \mathrm{O} 2 ; 175 \mathrm{~mm})$, and $C N(3 \mathrm{~mm})$ decreased the slope to 0.6 ) $\pm 0.26 \mathrm{Fl} . \mathrm{U} / \mathrm{min}$. Data are the mean of nine neurons. Similar results were observed in four experiments. $B, \mathrm{O}_{2}^{-}$levels can be influenced by NOS activity. The mean response of $n=13$ neurons is depicted by filled squares. Basal rate of HEt oxidation was depressed by $50 \mathrm{~K}$ application in most cells $(11 / 15)$ in this example. Neurons were washed immediately with $\mathrm{Mg}^{2+}$-free saline $(0 \mathrm{Mg})$ containing L-Arg $(L-A r g ; 3 \mathrm{~mm})$ and remained in $\mathrm{Mg}^{2+}$-free saline for the remainder of the experiment. NMDA $(100$ $\mu \mathrm{M})+\mathrm{L}$-Arg increased the rate of HEt oxidation from $1.9 \pm 0.05$ to $5.8 \pm 0.09 \mathrm{Fl} . \mathrm{U} /$ min in 13 neurons, but the rate remained constant in 2 neurons (open squares). Replacement of L-Arg with the NOS inhibitor $L N A(100 \mu \mathrm{M})$ resulted in an increase in slope in both of these neurons. This action was not attributable to direct radical scavenging by L-Arg or LNA (data not shown). Finally, $C N$ was able to block HEt oxidation in all cases. $C$, Basal rate of $\mathrm{O}_{2}^{-}$production was not decreased by $D P I(10 \mu \mathrm{M})$. DPI did not prevent the increase in $\mathrm{O}_{2}^{-}$production induced by $F C C P(1 \mu \mathrm{M})$. $D$, The $F C C P$ mediated increase in HEt oxidation was blocked by the NO-generator SNOC $(300$ $\mu \mathrm{M})$. The inhibition was long-lived after washout of SNOC despite the continued presence of FCCP. This action may be caused by consumption of $\mathrm{O}_{2}^{-}$by $\mathrm{NO}$ and peroxynitrite formation during SNOC presence, but may indicate an inhibition of $\mathrm{O}_{2}^{-}$ generation after SNOC washout. Data are the mean of 23 neurons. E, The SNOCmediated block of HEt oxidation is not caused by vehicle or cysteine. Recovery after $S N O C(100 \mu \mathrm{M})$ washout was quicker than for the case shown in $D$. Nitrate-free L-Cys $(L-C y s)$ was ineffective, whereas a second application of SNOC also blocked HEt oxidation. Data are the mean of 32 neurons.
dent-Newman-Keuls contrasts). Similar results were obtained with the chelator $o$-phenanthrolene (10 mM; data not shown).

A subpopulation of hippocampal pyramidal neurons is known to possess NOS (Valtschanoff et al., 1993; Chiang et al., 1994; Dinerman et al., 1994). NOS also can be activated by the increase in $\left[\mathrm{Ca}^{2+}\right]_{i}$ produced by glutamate receptor agonists (Lipton and Stamler, 1994) and previously has been shown to increase $\mathrm{O}_{2}^{-}$ production in rat neurons (Lafon-Cazal et al., 1993). NO might decrease the $\mathrm{O}_{2}^{-}$concentration via peroxynitrite formation similar to that seen in cell-free assays (Fig. 2). Alternatively, NOS is able to generate $\mathrm{O}_{2}^{-}$directly if the substrate $\mathrm{L}$-Arg is limiting (Pou et al., 1992; Culcasi et al., 1994). In the example shown in Figure 6B, most neurons increased $\mathrm{O}_{2}^{-}$production on treatment with NMDA + L-Arg, suggesting that weak, or no, NO generation took place. However, the two neurons depicted by the open symbols did not show an increase in HEt oxidation during NMDA stimulation until the NOS antagonist LNA was added. Inhibition of NOS by LNA would block peroxynitrite production and associated $\mathrm{O}_{2}^{-}$consumption. Overall, 12 of 48 neurons showed NMDA responses consistent with NOS activity and sensitivity to arginine derivatives (range $0-63 \%$ of neurons per experiment; $n=6$ experiments). The low numbers of neurons with active NOS are consistent with the low prevalence of diaphorase staining in CA1 and CA3 regions (range 2-32\% of pyramidal cells) (Valtschanoff et al., 1993) (but see also Dinerman et at., 1994).

Because diaphorase activity can produce $\mathrm{O}_{2}^{-}$directly in the absence of L-Arg, we also tested whether NOS contributed to basal and FCCP-stimulated $\mathrm{O}_{2}^{-}$generation. NOS and NADPH oxidase are blocked selectively by diphenylene iodonium (DPI) (Rossi, 1986; Stuehr et al., 1991). Application of DPI $(10 \mu \mathrm{M})$ failed to inhibit the basal rate of $\mathrm{O}_{2}^{-}$production and also failed to block the FCCP-mediated rise in slope (Fig. $6 C$; overall, $n=33$ neurons, 3 experiments). This was not unexpected, because NOS may not he active under these conditions and also perhaps as a consequence of the low percentage of neurons expressing NOS activity (Fig. $6 B$ ). The NO generator SNOC potently inhibited the FCCP-mediated oxidation of HEt (Fig. 6D,E). A 5 min exposure to $300 \mu \mathrm{M}$ SNOC suppressed the slope for $>15 \mathrm{~min}$ in the continued presence of FCCP. As discussed, this inhibition may be attributable to peroxynitrite formation during SNOC application 
Figure 7. HEt produced region-specific and timedependent staining in rat hippocampal slices. Two examples are shown. The top left panel shows a phase-contrast image of the $\mathrm{CA} 3 / \mathrm{CA} 2$ region with the prominent, translucent cell somas of the pyramidal neurons. The middle and right panels show Et staining at time $=0(t=0)$ and after 28 min under resting conditions $(t=+28 \mathrm{~min})$. Initial staining was slight and increased over time. The increase in Et fluorescence was largely localized to the pyramidal cell somas, proximal dendrites, and scattered cells. This also is evident in the example (CA3 region) in the bottom row. The width of each image originally was $1.3 \mathrm{~mm}$.

$t=0$
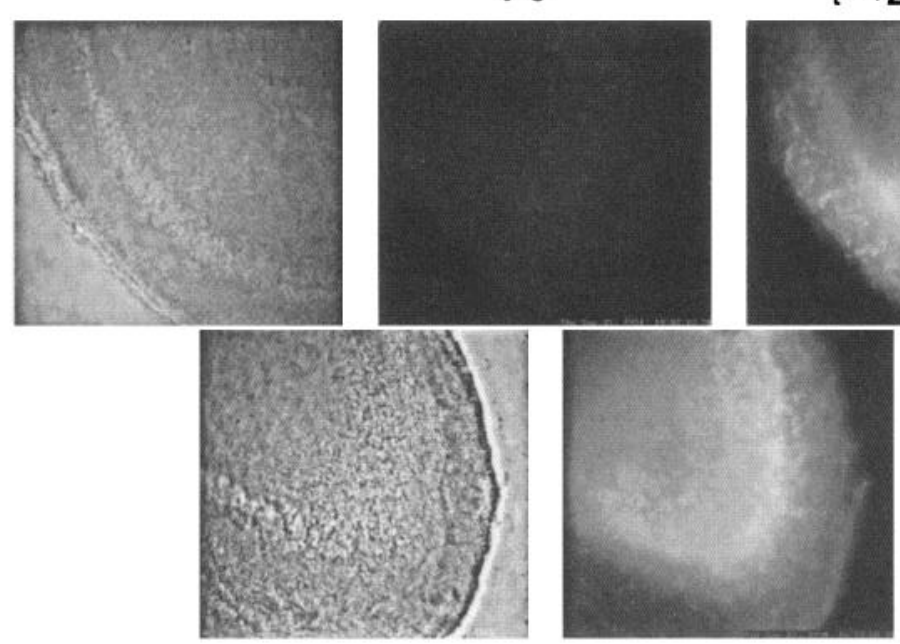

uniform spatially but, typically, hippocampal pyramidal neurons (especially CA1 and CA3) and the dentate gyrus stained heavily (Figs. 7, 8). Figure 7 shows two examples of the HEt staining. Most of the Et was localized to the pyramidal cell soma layer and dendrites. Similar to cultured cells, $\mathrm{O}_{2}^{-}$production was increased by NMDA, KA, and FCCP (data not shown). As seen in cell-free assays and in cultured neurons, $\mathrm{CN}$ and $\mathrm{NO}$ generation decreased HEt oxidation by $\mathrm{O}_{2}^{-}$(Fig. 8). Staining data are summarized in Figure $8 B$. The exogenous NO generators SNP and SNOC

\section{$\mathrm{O}_{2}^{-}$production in brain slices}

Treatment of hippocampal slices with HEt $(3.2 \mathrm{~nm})$ resulted in a time-dependent increase in fluorescence. The increases were not

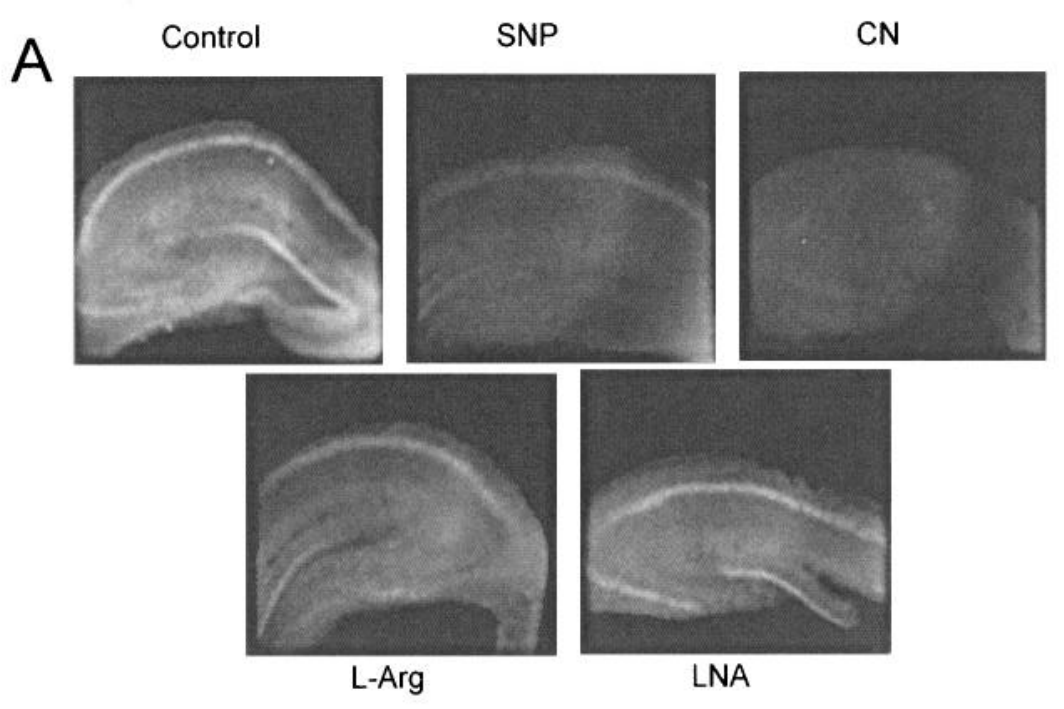

B

Figure 8. $A$, Oxidation of HEt to Et in rat hippocampal slices is reduced by $\mathrm{CN}$ and $\mathrm{NO}$ generators. Representative examples of the staining pattern after 20 min incubations in saline containing $3.2 \mu \mathrm{M}$ HEt are shown for Control, $300 \mu \mathrm{M} \mathrm{SNP,} 3$ $\mathrm{mm} C N, 3 \mathrm{~mm} L-A r g$, and $100 \mu \mathrm{M} L N A$. SNP and CN blocked Et accumulation in the pyramidal neuron soma layer; soma staining was reduced by L-Arg. The width of each image originally was $3.3 \mathrm{~mm}$. B, Summary of mean fluorescence intensity in hippocampal slices treated with $C N, S N P, S N O C$ $(300 \mu \mathrm{M}), L-A r g$, and $L N A$. All treatments except LNA produced a significant reduction in HEt oxidation $(p<0.05)$.

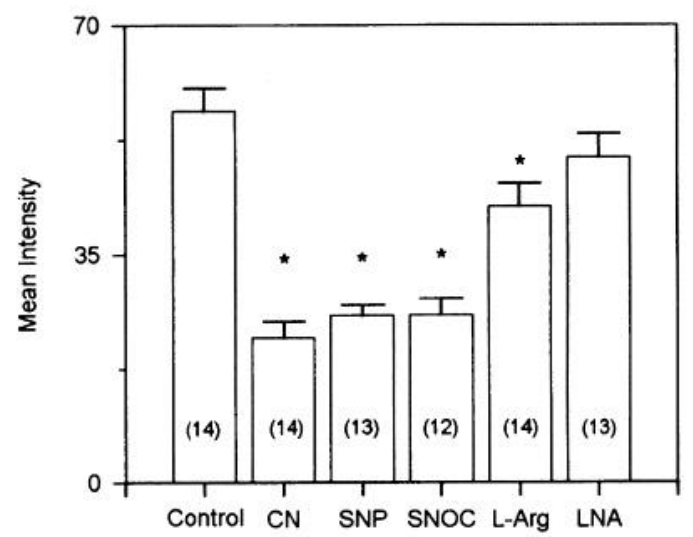


blocked basal rates of HEt oxidation effectively in brain slices. The basal oxidation rate was equally sensitive to block by $\mathrm{CN}^{-}$. Addition of L-Arg ( $3 \mathrm{~mm}$ ), the substrate for endogenous NOS, inhibited HEt oxidation significantly and suggests that NOS was active in slices. The NOS inhibitor LNA consistently decreased $\mathrm{O}_{2}^{-}$production slightly, albeit nonsignificantly, versus unstimulated controls, and typically reduced the effectiveness of L-Arg (data not shown). Similar results were obtained with DPI $(10 \mu \mathrm{M}$; data not shown). The data show that $\mathrm{O}_{2}^{-}$assay by $\mathrm{HEt}$ is applicable to tissue slice preparations and that $\mathrm{O}_{2}^{-}$concentration in rat hippocampal slices is sensitive to $\mathrm{CN}$ and NO.

The charged Et oxidation product and its ability to stain polynucleotides in cells that convert HEt provided a permanent record of cells that oxidized HEt. Slices could be fixed and retained Et record similar to tumor cells (Bucana et al., 1986). However, we found that the fluorescence intensity could decrease slightly during overnight fixation at $4^{\circ} \mathrm{C}$ (data not shown). The binding to DNA and RNA also may protect the Et from additional actions of ROS that may promote either the re-reduction of Et to HEt or its decomposition to nonfluorescent forms.

\section{DISCUSSION}

Among the numerous methods available for detecting ROS production in cells, there are none that are selective for $\mathrm{O}_{2}^{-}$and that also are able to indicate the site of its production. We have demonstrated that HEt is oxidized only by $\mathrm{O}_{2}^{-}$under the present assay conditions. The dye was not oxidized by $\cdot \mathrm{OH}, \mathrm{NO},{ }^{-} \mathrm{ONOO}$, $\mathrm{H}_{2} \mathrm{O}_{2}$, hypochlorite, or singlet $\mathrm{O}_{2}$. Compared with other fluorescent dyes, HEt displays good photostability, especially under the longer excitation wavelength used to observe the oxidation prod uct, Et. The higher quantum efficiency of Et bound to DNA enhanced detection. The method was amenable to kinetic measurements of $\mathrm{O}_{2}^{-}$production, and the stable oxidized product allowed tissues to be fixed and used for end-point analyses. Thus far, HEt has been used primarily in flow-cytometric studies (Olive, 1989; Rothe and Valet, 1990; Perticarari et al., 1991; Shi et al., 1991) and can be used in some plate readers for automated analyses (Bucana et al., 1986; Saiki et al., 1986). We have demonstrated now that the HEt method has distinct advantages for analyzing $\mathrm{O}_{2}^{-}$production in a variety of neuronal preparations by digital imaging microfluorimetry.

One of the possible limitations of HEt as an indicator for the quantitation of $\mathrm{O}_{2}^{-}$production is the $\sim 20$-fold increase in quantum efficiency that occurs with the binding of Et to DNA or RNA (LePecq and Paoletti, 1967). Absolute quantitation of $\mathrm{O}_{2}^{-}$, therefore, must consider the presence of DNA and RNA. This complication is weighed by the possibility that the intercalation of Et into polynucleotides also serves to protect the Ft from additional oxidation/reduction and also provides a permanent record of cells that oxidized HEt. Et generated outside of cells (e.g., by phagocytes) will be excluded from the nucleus, provided that cell membranes remain intact, in accord with the use of Et and similar dyes in cell viability assays. Another possible disadvantage is the nonratiometric measurement of Et fluorescence. Despite the fact that HEt is fluorescent, it may be ill suited for ratios because of its possible sequestration into vesicles (Bucana et al., 1986; Saiki et al., 1986), although not observed in neurons in present studies, and the short excitation wavelength would promote photooxidation. Although high concentrations $(>100 \mu \mathrm{M})$ of Et can interfere with mitochondrial respiration (Miko and Chance, 1975), our standard imaging conditions permitted detection of Et estimated to range between $10 \mathrm{~nm}$ and $30 \mu \mathrm{m}$ (Fig. 1D) and, therefore, avoided potential acute toxicity of Et.

Cell-free assays demonstrated that HEt oxidation was mediated by $\mathrm{O}_{2}^{-}$(Fig. 2) generated with $\mathrm{KO}_{2}$ (Fig. $1 E$ ), as reported previously (Rothe and Valet, 1990), and by X + XO (Fig. 2), and was blocked by $\mathrm{Cu} / \mathrm{Zn}-\mathrm{SOD}$ (Fig. 2A). A 1:1 molar ratio for the interaction of $\mathrm{HEt}$ with $\mathrm{O}_{2}^{-}$has been reported recently (Biziukin and Korkina, 1994). The obscrved insensitivity to $\mathrm{OH}$ probably is the result of the relatively low concentration of $\mathrm{HEt}$ compared with the $\sim 4300$ - and 3100 -fold excesses of the potent $\mathrm{OH}$ scavengers DMSO and HEPES, and perhaps the trapping of $\mathrm{O}_{2}^{-}$ before its conversion to $\cdot \mathrm{OH}$. Because DMSO is freely permeable, it seems unlikely that any cellular domain would escape the $\cdot \mathrm{OH}$ scavenging and react with $\mathrm{HEt}$ to generate a significant Et signal. Insensitivity to ${ }^{-}$ONOO was shown by the low conversion produced by the ${ }^{-}$ONOO generator morpholinosydnonimine (SIN-1; Fig. $2 B$ ) and by the inhibition of HEt oxidation in $\mathrm{XO}+\mathrm{X}+\mathrm{NO}$ generators (Fig. $2 B, C$ ). The assay thus may underestimate total $\mathrm{O}_{2}^{-}$production if there are high concentrations of dismutases or competing scavengers. By the same reasoning, changes in $\mathrm{HEt}$ oxidation rate can be used as an indirect measure of these competing processes.

The rate of HEt oxidation varied greatly in different types of cells but always excecded the auto-oxidation rate seen in cell-free assays. The basal rate of $\mathrm{O}_{2}^{-}$generation increased as cultured neurons aged (Fig. $4 B$ ). The highest rates typically were observed in senescing cultures, in accord with previous reports (Nohl and Hegner, 1978; Shigenaga et al., 1994).

Depolarization $(50 \mathrm{~K})$ did not increase $\mathrm{O}_{2}^{-}$generation measured by $\mathrm{HEt}$ (Fig. $4 C$ ), but this may be an aberration attributable to swelling of the soma. Increased $\mathrm{O}_{2}^{-}$production was observed for depolarization in $\mathrm{Na}^{+}$-free saline, in which swelling was minimal. An alternate explanation is related to differences in $\left[\mathrm{Ca}^{2+}\right]_{i}$ in $\mathrm{Na}^{+}$-free saline (see below).

Our data extend previous reports (Bondy and Lee, 1993; LafonCazal et al., 1993; Marin et al., 1993; Culcasi et al., 1994) that glutamate receptor agonists increase $\mathrm{O}_{2}^{-}$production by demonstrating changes in $\mathrm{O}_{2}^{-}$production within individual hippocampal neurons. This increase did not occur in glia. Neuronal $\mathrm{O}_{2}^{-}$production increased after treatment with AMPA (data not shown), KA (Figs. $4 D, 5 A, F$ ), and NMDA (Figs. $5 B, D, E, 6 B$ ). The NMDAmediated increase was small or absent in neurons younger than 8 DIV, presumably because of lack of development of NMDA receptors at this stage (data not shown). In mature neurons, $\mathrm{O}_{2}^{-}$ generation increased roughly twofold after treatment with NMDA (Fig. 5). The lag between NMDA application and the rise in $\mathrm{O}_{2}^{-}$ production also varied in different neurons (Fig. 3). The nondditivity of treatments that increased $\mathrm{O}_{2}^{-}$production, for example, the lack of additional increase in $\mathrm{O}_{2}^{-}$production by $\mathrm{FCCP}$ in neurons with high rates of $\mathrm{O}_{2}^{-}$generation after NMDA treatment (Fig. 5), suggested that either cellular $\mathrm{O}_{2}^{-}$production or its reporting by HEt could be saturated. Because this ceiling was observed in cells with widely varying rates of HEt oxidation, we favor the hypothesis that $\mathrm{O}_{2}$ production was saturable.

\section{Role of $\left[\mathrm{Ca}^{2+}\right]_{\mathrm{i}}$ in $\mathrm{O}_{2}^{-}$generation}

Enhanced $\mathrm{O}_{2}^{-}$production appeared to require $\mathrm{Ca}^{2+}$ entry, because little effect was observed when KA or NMDA was applied in $\mathrm{Ca}^{2+}$-free saline (Fig. 5). On the other hand, short application of a $\mathrm{Ca}^{21}$ ionophore producing $\left[\mathrm{Ca}^{2+}\right]_{i}$ that equaled or execeded that produced by glutamate agonists (Prehn et al., 1994) did not increase $\mathrm{O}_{2}^{-}$production greatly (Fig. $5 D, E$ ). Similar results were 
observed in a rat brain microsac preparation (Bondy and Lee, 1993). A high $\left[\mathrm{Ca}^{2+}\right]_{\mathrm{i}}$ requirement for $\mathrm{ROS}$ generation by isolated mitochondria was demonstrated by Dykens (1994). However, maximal ROS generation in that study required the presence of high intracellular $\mathrm{Na}^{+}$and $\mathrm{Ca}^{2+}$. Nevertheless, it appears that high $\left[\mathrm{Ca}^{2+}\right]_{\mathrm{i}}$ may be sufficient for enhanced $\mathrm{O}_{2}^{-}$production in intact neurons, because rate increases were observed for KA (Fig. $6 A$ ) and NMDA (data not shown) applied in $\mathrm{Na}^{+}$-free saline.

The route and intracellular localization of the $\left[\mathrm{Ca}^{2+}\right]_{i}$ signal may be important parameters for enhancement of $\mathrm{O}_{2}^{-}$generation, because $\mathrm{O}_{2}^{-}$production did not increase greatly after $\mathrm{Ca}^{2+}$ ionophore or $50 \mathrm{~K}$ depolarization. The importance of entry locus or intracellular compartment also may explain why only certain mitochondria appeared to oxidize HEt (Fig. 3C). Perhaps these mitochondria reside near synaptic areas containing high concentrations of receptors and thus are exposed to large $\left[\mathrm{Ca}^{2+}\right]_{i}$ gradients. Indeed, we have demonstrated recently that initial sites of neurodegeneration produced by KA stimulation are associated with such domains of high $\left[\mathrm{Ca}^{2+}\right]_{i}$ at synapses (Bindokas and Miller, 1995). Much of this $\mathrm{Ca}^{2+}$ can be seen to enter the mitochondria. High microdomain concentrations of $\left[\mathrm{Ca}^{2+}\right]_{i}$ thus may be critical for increasing $\mathrm{O}_{2}^{-}$generation. Hepatocyle mitochondrial state similarly was found to be influenced more by inositol triphosphate-mediated $\left[\mathrm{Ca}^{2+}\right]_{i}$ elevations than by sustained elevations of $\left[\mathrm{Ca}^{2+}\right]_{\mathrm{i}}$ (Hajnóczky et al., 1995). It is interesting to note that $50 \mathrm{~K}$ was able to increase $\mathrm{O}_{2}^{-}$generation in the absence of extracellular $\mathrm{Na}^{+}$. With $\mathrm{Ca}^{2+}$ removal compromised by lack of $\mathrm{Na}-\mathrm{Ca}$ exchange, $\mathrm{Ca}^{2+}$ influx through voltage-sensitive $\mathrm{Ca}^{2+}$ channels now may be more influential. It seems likely that increased $\left[\mathrm{Ca}^{2+}\right]_{i}$ provides a link between glutamate receptor stimulation, mitochondrial function, and $\mathrm{O}_{2}^{-}$generation.

\section{Role of mitochondria in $\mathbf{O}_{2}^{-}$generation}

It is estimated that $1-2 \%$ (Turrens and Boveris, 1980) of the electron flow in mitochondria normally leaks from the electron transport chain to form $\mathrm{O}_{2}^{-}$and that $20 \%$ of the $\mathrm{O}_{2}^{--}$escapes mitochondrial SOD (Nohl and Hegner, 1978). $\mathrm{O}_{2}^{-}$may arise via ubisemiquinone oxidation or NADH dehydrogenase activity (cf. Turrens et al., 1985; Nohl, 1990). Our data are consistent with mitochondrial respiration as the main source of the basal $\mathrm{O}_{2}^{-}$ production and as the major source of the FCCP-, $\mathrm{H}_{2} \mathrm{O}_{2}^{-}$, and glutamate-receptor agonist-activated $\mathrm{O}_{2}^{-}$production. In support of this conclusion, the initial Et staining pattern was colocalized with a population of R123-stained mitochondria (Fig. 3C) similar to that recently reported by Reynolds and Hastings (1995). Block of the respiratory chain with $\mathrm{CN}$ could eliminate basal $\mathrm{O}_{2}^{-}$generation completely (Fig. $5 \mathrm{C}$ ). We are not aware of any other effects of FCCP or CN other than on mitochondrial state that would explain the observed $\mathrm{O}_{2}^{-}$rate data. Because NOS did not contribute to basal $\mathrm{O}_{2}^{-}$generation in cultured neurons (Fig. 6C), the inhibition of $\mathrm{O}_{2}^{-}$production was not attributable to possible inhibition of NOS by CN (Hobbs et al., 1994). Of interest, the protonophore FCCP was able to restore $\mathrm{HEt}$ oxidation in $\mathrm{CN}$ blocked neurons (Fig. $5 C$ ). FCCP acts to stimulate mitochondrial electron transport maximally, suggesting that the increase in $\mathrm{O}_{2}^{-}$ generation was caused by increased mitochondrial respiration. This also implicates ubisemiquinone as the major leak site, because $\mathrm{O}_{2}^{-}$generation by ubisemiquinone in isolated preparations has been observed under similar conditions (Nohl, 1990). The production of $\mathrm{O}_{2}^{-}$in the presence of KA and NMDA was inhibited by $\mathrm{CN}$ (see Fig. 5), but neurons with especially high rates of $\mathrm{O}_{2}^{-}$production continued to generate $\mathrm{O}_{2}^{-}$at a slower rate. This suggests that $\mathrm{O}_{2}^{-}$can be generated by other mechanisms as well (cf. Siesjö et al., 1989).

It is noteworthy that some neurons (e.g., superior cervical ganglion cells) and glia present in some hippocampal cultures appeared to have especially low rates of $\mathrm{O}_{2}^{-}$production and often were unaffected by FCCP (data not shown). Because it is unlikely that FCCP failed to uncouple respiration, either these cells did not produce large concentrations of $\mathrm{O}_{2}^{-}$via electron transport or, more likely, they possessed more efficient ROS-scavenging mechanisms. For example, glial cells have been shown to have significantly higher glutathione content (Sagara et al., 1993).

$\mathrm{H}_{2} \mathrm{O}_{2}$ is toxic to cells and recently has been shown to secondarily generate $\mathrm{O}_{2}$ in endothelial cells (Carter et al., 1994). Application of $\mathrm{H}_{2} \mathrm{O}_{2}$ increased or promoted HEt oxidation in all cells tested. This may be attributable to $\mathrm{H}_{2} \mathrm{O}_{2}$ overwhelming cellular defense mechanisms (for example, by blocking $\mathrm{Cu} / \mathrm{Zn}-\mathrm{SOD}$ ) and unmasking $\mathrm{O}_{2}^{-}$production normally undetected, and/or an actual increase in production of $\mathrm{O}_{2}^{-}$. This is consistent with the increase in HEt oxidation observed after treatment with the $\mathrm{Cu}^{2+}$ chelators APDC and $o$-phenanthrolene. The effect of $\mathrm{H}_{2} \mathrm{O}_{2}$ was not additive in cells that already had a high rate of $\mathrm{O}_{2}^{-}$production because of treatnent wilh FCCP, KA, or NMDA (see Fig. 5E), and was sensitive to block by $\mathrm{CN}$ (Fig. $6 A$ ). Because $\mathrm{O}_{2}^{-}$dismutates spontaneously or by enzymatic action to $\mathrm{H}_{2} \mathrm{O}_{2}$ and inhibits catalase (Kono and Fridovich, 1982), and its generation is enhanced by $\mathrm{H}_{2} \mathrm{O}_{2}$, this could create a regenerative cycle that magnifies oxidative damage to cellular components.

It has been reported that NOS and other NADPH oxidases can generate $\mathrm{O}_{2}$ under certain conditions (Pou et al., 1992; Culcasi et al., 1994). The selective inhibitor diphenylene iodonium (Stuehr et al., 1991) failed to block the basal rate of $\mathrm{O}_{2}^{-}$production as well as the FCCP-stimulated increase in cultured cells (Fig. 6C), suggesting that these oxidases are not active under these conditions. Exogenous generation of NO did inhibit the oxidation of Et by $\mathrm{X} / \mathrm{XO}$ (Fig. 2) and within neurons (Fig. 6). This action probably was caused by $\mathrm{O}_{2}^{-}$consumption via peroxynitrite formation (Lipton et al., 1993). The prolonged suppression of FCCP-stimulated $\mathrm{O}_{2}^{-}$generation after $\mathrm{NO}$ may be an indication that nitrogen radicals disrupt mitochondrial electron transport. Various cytochromes and enzymes, as well as mitochondrial potential, are known to be sensitive to NO or ${ }^{-}$ONOO (Bolanos et al., 1994; Cleeter et al., 1994; Schweizer and Richter, 1994).

Slices of rat hippocampi showed time-dependent staining intensity primarily in neuronal somas from pyramidal layers and dentate gyrus (Figs. 7,8). Staining was sensitive to $\mathrm{CN}$ and NO similar to that observed in cultured neurons (Fig. 8). Increasing the L-Arg concentration reduced staining significantly, presumably by stim ulating NOS activity. NOS inhibitors reduced this effect. The slight but consistent reduction of baseline $\mathrm{O}_{2}^{-}$production by NOS inhibitors suggests further that NOS activity is an important regulator of $\mathrm{O}_{2}^{-}$levels in brain slices.

Given the success of the assay of $\mathrm{O}_{2}^{-}$production within slice preparations, it also may be possible to monitor $\mathrm{O}_{2}^{-}$production in whole tissue by using HEt in perfusion solutions. This would allow end-point monitoring of $\mathrm{O}_{2}^{-}$production during situations such as ischemia/reperfusion.

\section{REFERENCES}

Abele AE, Scholz K, Miller RJ, Scholz WK (1990) Excitotoxicity induced by enhanced excitatory neurotransmission in cultured hippocampal neurons. Neuron 4:413-419.

Bass DA, Parce JW, Dechatelet LR, Szejda P, Seeds MC, Thomas M (1983) Flow cytometric studies of oxidative product formation by neu- 
trophils: a graded response to membrane stimulation. $\mathbf{J}$ Immunol 130:1910-1917.

Bensasson RV, Land EJ, Truscott TG (1993) Excited states and free radicals in medicine: contributions from flash photolysis and pulse radiolysis. New York: Oxford UP.

Bindokas VP, Miller RJ (1995) Excitotoxic degeneration is initiated at non-random sites in cultured rat cerebellar neurons. I Neurosci 15:6999-7011.

Biziukin AV, Korkina LG (1994) Use of the fluorescent indicator hydroethidine to study the oxidative metabolism of phagocytes [in Russian]. Klin Lab Diagn 1:41-42.

Bolaños JP, Peuchen S, Heales SJR, Land JM, Clark JB (1994) Nitric oxide-mediated inhibition of the mitochondrial respiratory chain in cultured astrocytes. J Neurochem 63:910-916.

Bondy SC, Lee DK (1993) Oxidative stress induced by glutamate receptor agonists. Brain Res 610:229-233.

Bucana C, Saiki I, Nayar R (1986) Uptake and accumulation of the vital dye hydroethidine in neoplastic cells. J Histochem Cytochem 34:1109-1115.

Cadenas E (1989) Biochemistry of oxygen toxicity. Annu Rev Biochem 58:79-110.

Carter WO, Narayanan PK, Robinson JP (1994) Intracellular hydrogen peroxide and superoxide anion detection in endothelial cells. J Leukocyte Biol 55:253-258.

Cathcart R, Schwiers E, Ames BN (1983) Detection of picomole levels of hydroperoxides using a fiuorescent dichlorofluorescein assay. Anal Chem 134:111-116.

Chiang LW, Schweizer FE, Tsien RW, Schulman H (1994) Nitric oxide synthase expression in single hippocampal neurons. Mol Brain Res 27:183-188.

Cleeter MWJ, Cooper JM, Darley-Usmar VM, Moncada S, Schapira AHV (1994) Reversible inhibition of cytochrome $C$ oxidase, the terminal enzyme of the mitochondrial respiratory chain, by nitric oxide. FEBS Lett 345:50-54.

Coyle JT, Puttfarcken P (1993) Oxidative stress, glutamate, and neurodegenerative disorders. Science 262:689-695.

Culcasi M, Lafon-Cazal M, Pietri S, Bockaert J (1994) Glutamate receptors induce a burst of superoxide via activation of nitric oxide synthase in arginine-depleted neurons. J Biol Chem 269:12589-12593.

Dawson TM, Snyder SH (1994) Gases as biological messengers: nitric oxide and carbon monoxide in the brain. J Neurosci 14:5147-5159.

Dinerman JL, Dawson TM, Schell MJ, Snowman A, Snyder SH (1994) Endothelial nitric oxide synthase localized to hippocampal pyramidal cells: implications for synaptic plasticity. Proc Natl Acad Sci USA 91:4214-4218

Dugan LL, Sensi SL, Canzoniero LMT, Goldberg MP, Handran SM, Rothman SM, Choi DW (1994) Imaging of mitochondrial oxygen radical production in cortical neurons exposed to NMDA. Soc Neurosci Abstr 20:1532

Dykens JA (1994) Isolated cerebral and cerebellar mitochondria produce free radicals when exposed to elevated $\mathrm{Ca}^{2+}$ and $\mathrm{Na}^{+}$: implications for neurodegeneration. J Neurochem 63:584-591.

Elstner EF, Heupel A (1976) Inhibition of nitrite formation from hydroxylammonium-chloride: a simple assay for superoxide dismutase. Anal Biochem 70:616-620.

Emaus RK, Grunwald R, Lemasters JJ (1986) Rhodamine 123 as a probe of transmembrane potential in isolated rat-liver mitochondria: spectral and metabolic properties. Biochim Biophys Acta 850:436-448.

Fabian RH, DeWitt DS, Kent TA (1995) In vivo detection of superoxide anion production by the brain using a cytochrone $\mathrm{C}$ electrude. J Cereb Blood Flow Metab 15:242-247.

Feelisch M (1991) The biochemical pathways of nitric oxide formation from nitrovasodilators: appropriate choice of exogenous NO donors and aspects of preparation and handling of aqueous NO solutions. J Cardiovasc Pharmacol 17「Suppl 31:S25-S33.

Feelisch M, Ostrowski J, Noack E (1989) On the mechanism of NO release from sydnonimines. $\mathbf{J}$ Cardiovasc Pharmacol 14[Suppl 11]:S13-S27.

Forman HJ, Kennedy J (1976) Dihydroorotate-dependent superoxide production in rat brain and liver. Arch Biochem Biophys 173:219-224.

Gallop PM, Paz MA, Henson E, Latt SA (1984) Dynamic approaches to the delivery of reporter reagents into living cells. Biotechniques 3:32-36.

Hajnóczky G, Robb-Gaspers LD, Seitz MB, Thomas AP (1995) Decoding of cytosolic calcium oscillations in mitochondria. Cell $82: 415-424$
Halliwell B (1989) Oxidants and the central nervous system: some fundamental questions. Is oxidant damage relevant to Parkinson's disease, Alzheimer's disease, traumatic injury or stroke? Acta Neurol Scand 126:23-33.

Halliwell B, Gutteridge JMC (1984) Oxygen toxicity, oxygen radicals, transition metals and disease. Biochem J 219:1-14.

Hobbs AJ, Fukuto JM, Ignarro LJ (1994) Formation of free nitric oxide from L-arginine by nitric oxide synthase: direct enhancement of generation by superoxide dismutase. Proc Natl Acad Sci USA 91:10992-10996.

Hogg N, Darley-Usmar M, Wilson MT, Moncada S (1992) Production of hydroxyl radicals from the simultaneous generation of superoxide and nitric oxide. Biochem J 281:419-424.

Huie RE, Padmaja S (1993) The reaction rate of nitric oxide with superoxide. Free Radic Res Commun 18:195-199.

Ignarro LJ (1990) Nitric oxide: a novel signal transduction mechanism for transcellular communication. Hypertension 16:477-483.

Ikeda Y, Long DM (1990) The molecular basis of brain injury and brain edema: the role of oxygen free radicals. Neurosurgery 27:1-11.

Iqbal J, Whitney P (1991) Use of cyanide and diethyldithiocarbamate in the assay of superoxide dismutases. Free Radic Biol Med 10:69-77.

Key Jr LL, Rics WL, Taylor RG, Hays BD, Pitzer BL (1990) Oxygen derived free radicals in osteoclasts: the specificity and localization of the nitroblue tetrazolium reaction. Bone 11:115-119.

Kono Y, Fridovich I (1982) Superoxide radical inhibits catalase. J Biol Chem 257:5751-5754.

Koody NW, Royall JA, Ischiropoulos H, Beckman JS (1994) Peroxynitrite-mediated oxidation of dihydrorhodamine 123. Free Radic Biol Med 16:149-156.

Kuppusamy P, Zweier JL (1989) Characterization of free radical generation by xanthine oxidase. J Biol Chem 264:9880-9884.

Lafon-Cazal M, Pietri S, Culcasi M, Bockaert J (1993)NMDA-dependent superoxide production and neurotoxicity. Nature 364:535-537.

Lei SZ, Pan Z-P, Aggarwal SK, Vincent Chen II-S, I Iartman J, Sucher NJ, Lipton SA (1992) Effect of nitric oxide on the redox modulatory site of the NMDA receptor-channel complex. Neuron 8:1087-1099.

LePecq J-B, Paoletti C (1967) A fluorescent complex between cthidium bromide and nucleic acids: physical-chemical characterization. J Med Biol 27:87-106.

Lipton SA, Stamler JS (1994) Actions of redox-related congeners of nitric oxide at the NMDA receptor. Neuropharmacology 33:1229-1233.

Lipton SA, Choi Y-B, Pan Z-H, Lei SZ, Vincent Chen H S, Sucher NJ, Loscalzo J, Singel DJ, Stamler JS (1993) A redox-based mechanism for the neuroprotective and neurodestructive effects of nitric oxide and related nitroso-compounds. Nature 364:626-632.

Lissi E, Pascual C, Del Castillo MD (1994) On the use of the quenching of luminol luminescence to evaluate SOD activity. Free Radic Biol Med 16:833-837.

Lokesh BR, Cunningham ML (1986) Further studies on the formation of oxygen radicals by potassium superoxide in aqueous medium for biochemical investigations. Toxicol Lett 34:75-84.

Lynch RE, Fridovich I (1978) Permeation of the erythrocyte stroma by superoxide radical. J Biol Chem 253:4697-4699.

Maines MD (1993) Carbon monoxide: an emerging regulator of cGMP in the brain. Mol Cell Neurosci 4:389-397.

Marin P, Quignard J-F, Lafon-Cazal M, Bockaert J (1993) Non-classical glutamate receptors, blocked by both NMDA and non-NMDA antagonists, stimulate nitric oxide production in neurons. Neuropharmacology $32: 29-36$.

Miko M, Chance B (1975) Ethidium bromide as an uncoupler of oxidative phosphorylation. FEBS Lett 54:347-352.

Nakano M (1990) Determination of superoxide radical and singlet oxygen based on chemiluminescence of luciferin analogs. Methods Enzymol 186:585-591.

Nohl H (1990) Is redox-cycling ubiquinone involved in mitochondrial oxygen activation? Free Radic Res Commun 8:4-6.

Nohl H, Hegner D (1978) Do mitochondria produce oxygen radicals in vivo? Eur J Biochem 82:563-567.

Olive PL (1989) Hydroethidine: a fluorescent redox probe for locating hypoxic cells in spheroid tumours. Br J Cancer 60:332-338.

Perticarari S, Presani G, Mangiarotti MA, Banfi E (1991) Simultaneous flow cytometric method to measure phagocytosis and oxidative products by neutrophils. Cytometry 12:687-693. 
Pou S, Pou WS, Bredt DS, Snyder SH, Rosen GM (1992) Generation of superoxide by purified brain nitric oxide. J Biol Chem 267:24173-24176.

Prehn JHM, Bindokas VP, Marcuccilli CJ, Krajewski S, Reed JC, Miller RJ (1994) Regulation of neuronal Bcl'2 protein expression and calcium homeostasis by transforming growth factor type $\beta$ confers wide-ranging protection on rat hippocampal neurons. Proc Natl Acad Sci USA 91:12599-12603.

Reynolds IJ, Hastings TG (1995) Glutamate induces the production of reactive oxygen species in cultured forebrain neurons following NMDA receptor activation. J Neurosci 15:3316-3327.

Rossi $\mathrm{F}$ (1986) The $\mathrm{O}_{2}^{-}$-forming NADPH oxidase of phagocytes: nature, mechanisms of activation and function. Biochim Biophys $\Lambda$ cta 853:65 89.

Rothe G, Valet G (1990) Flow cytometric analysis of respiratory burst activity in phagocytes with hydroethidine and $2^{\prime}, 7^{\prime}$-dichlorofluorescin. $\mathbf{J}$ Leukocyle Biol 47:440-448.

Sagara J-I, Miura K, Bannai S (1993) Maintenance of neuronal glutathatione by glial cells. J Neurochem 61:1672-1676.

Saiki I, Bucana C, Tsao JY, Fidler IJ (1986) Quantitative fluorescent microassay for identification of antiproliferative compounds. J Natl Cancer Inst 77:1235-1240.

Scaduto Jr RC (1995) Oxidation of DMSO and methanesulfinic acid by the hydroxyl radical. Free Radic Biol Med 18:271-277.

Schweizer M, Richter C (1994) Nitric oxide potently and reversibly deenergizes mitochondria at low oxygen tension. Biochem Biophys Res Commun 204:169-175

Shi T, Eaton AM, Ring DB (1991) Selection of hybrid hybridomas by flow cytometry using a new combination of fluorescent vital stains. $\mathrm{J}$ Immunol Methods 141:165-175.

Shigenaga MK, Hagen TM, Ames BA (1994) Oxidative damage and mitochondrial decay in aging. Proc Natl Acad Sci USA 91:10711-10778.

Siesiö BK, Agardh C-D, Bengtsson F (1989) Free radicals and brain damage. Cerebrovasc Brain Metab Rev 1:165-211.
Smith RP, Wilcox DE (1994) Toxicology of selected nitric oxidedonating xenobiotics, with particular reference to azide. Crit Rev Toxicol 24:355-377.

Steinbeck MJ, Khan AU, Appel Jr WH, Karnovsky MJ (1993) The DAB$\mathrm{Mn}^{++}$cytochemical method revisited: validation of specificity for superoxide. J Histochem Cytochem 41:1659-1667.

Stuehr D.I, Fasehun OA, Kwon NS, Gross SS, Gonzalez. IA, I evi R, Nathan CF (1991) Inhibition of macrophage and endothelial cells nitric oxide synthase by diphenyliodonium and its analogs. FASEB J 5:98-103.

Swannell RPJ, Caplin R, Nedwell DB, Williamson FA (1992) An investigation of hydroethidine as a fluorescent vital stain for prokaryotes. FEMS Microbiol Ecol 101:173-182.

Tanaka M, Sotomatsu A, Yoshida T, Hirai S, Nishida A (1994) Detection of superoxide production by activated microglia using a sensitive and specific chemiluminescence assay and microglia-mediated $\mathrm{PC} 12 \mathrm{~h}$ cell death. J Neurochem 63:266-270.

Traystman RJ, Kirsch JR, Koehler RC (1991) Oxygen radical mechanisms of brain injury following ischemia and reperfusion. $\mathrm{J} \Lambda \mathrm{ppl}$ Physiol 71:1185-1195.

Tsien RY (1989) Fluorescent indicators of ion concentrations. Methods Cell Biol 30:127-156.

Turrens JF, Boveris A (1980) Generation of superoxide anion by the NADH dehydrogenase of bovine heart mitochondria. Biochem J 191:421-427.

Turrens JF, Alexander A, Lehninger AL (1985) Ubisemiquinone is the electron donor for superoxide formation by complex III of heart mitochondria. Arch Biochem Biophys 237:408-414.

Valtschanoff JG, Weinberg RJ, Kharazia VN, Nakane M, Schmidt HHHW (1993) Neurons in the rat hippocampus that synthesize nitric oxide. J Comp Neurol 331:111-121.

Zhu H, Bannenberg GL, Moldéus P, Shertzer HG (1994) Oxidation pathways for the intracellular probe $2^{\prime}, 7^{\prime}$-dichlorofluorescin. Arch Toxicol 68:582-587. 